\title{
Developing a Batch Isolation Procedure and Running It in an Automated Semicontinuous Unit: AWL CFD25 Case Study
}

Sara Ottoboni,* Muhid Shahid, Christopher Steven, Simon Coleman, Elisabeth Meehan, Alastair Barton, Paul Firth, Richard Sutherland, and Chris J. Price

Cite This: Org. Process Res. Dev. 2020, 24, 520-539

Read Online

ABSTRACT: A key challenge during the transition from laboratory/small batch to continuous manufacturing is the development of a process strategy that can easily be adopted for a larger batch/continuous process. Industrial practice is to develop the isolation strategy for a new drug/process in batch using the design of experiment (DoE) approach to determine the best isolation conditions and then transfer the isolation parameters selected to a large batch equipment/continuous isolation process. This stage requires a series of extra investigations to evaluate the effect of different equipment geometry or even the adaptation of the parameters selected to a different isolation mechanism (e.g., from dead end to cross flow filtration) with a consequent increase of R\&D cost and time along with an increase in material consumption. The CFD25 is an isolation device used in the first instance to develop an isolation strategy in batch (optimization mode) using a screening DoE approach and to then verify the transferability of the strategy to a semicontinuous process (production mode). A d-optimal screening DoE was used to determine the effect of varying the input slurry. Properties such as solid loading, particle size distribution, and crystallization solvent were investigated to determine their impact on the filtration and washing performance and the characteristics of the dry isolated product. A series of crystallization (ethanol, isopropanol, and 3-methylbutan-1-ol) and wash solvents ( $n$-heptane, isopropyl acetate and $n$-dodcane) were used for the process. To mimic a real isolation process, paracetamol-related impurities, acetanilide and metacetamol, were dissolved in the mother liquor. The selected batch isolation strategy was used for the semicontinuous isolation run. Throughput and filtration parameters, such as cake resistance and flow rate, cake residual liquid content and composition, cake purity, particle-particle aggregation, and extent and strength of agglomerates, were measured to evaluate the consistency of the isolated product produced during a continuous experiment and compared with the isolated product properties obtained during the batch process development. Overall, the CFD25 is a versatile tool which allows both new chemical entity process development in batch and the production of the active pharmaceutical ingredient in semicontinuous mode using the same process parameters without changing equipment. The isolated product properties gained during the semicontinuous run are overall comparable between samples. The residual solvent content and composition differs between some samples due to filter plate blockage. In general, the mean properties obtained during semicontinuous running are comparable with the product properties simulated using the DoE.

KEYWORDS: batch and semicontinuous isolation, analytical procedure, agglomeration, isolation strategy, optimization

\section{INTRODUCTION}

A key challenge facing the pharmaceutical industry is maintaining particle properties across the entire purification and isolation process. In the last decade, there has been substantial effort into crystal engineering to generate particles in suspension with the required size, habit, and other critical attributes. However, the task of maintaining these desirable particle properties during downstream isolation has received less attention. Active pharmaceutical ingredient (API) isolation by filtration, washing, and drying still poses significant challenges if practitioners are to avoid unwanted crystal attrition or agglomeration or precipitating dissolved product or impurities. ${ }^{1,2}$ Without effective washing, impurities which are in solution in the filtrate, some of which is retained in the filter cake, are incorporated in the product during drying, reducing purity. Any residual dissolved solute is also deposited and tends to promote granulation, changing the product particle size distribution (PSD). ${ }^{3}$ A washing step is invariably employed to minimize these problems. ${ }^{4}$ The final product attributes can be affected by different process and physicochemical parameters such as the feed suspension viscosity and density, PSD, suspended particle loading, ${ }^{5-10}$ the chemical character of impurities, ${ }^{11}$ the interactions between solvents during washing and drying, ${ }^{12-14}$ the point at which filtration is halted (dry land or breakthrough), the pressure driving force for both filtration and washing, etc. All of these processes and material attributes can affect the isolated crystal attributes (PSD, aspect ratio, and purity), filtration rate, efficiency of washing, and propensity for filter blockage. ${ }^{15-19}$ Equipment design affects the filtration performance. Therefore, decisions taken during the isolation stage can modify the particle characteristics. It is crucial to

Received: November 29, 2019

Published: March 26, 2020 
design the isolation process to maintain the required properties of the crystals obtained during crystallization.

The pharmaceutical industry is starting to adopt continuous API manufacturing in order to reduce the cost of production, improve manufacturing flexibility, and reduce infrastructure cost. It is also anticipated that continuous processing will improve consistency of API critical quality attributes, to reduce manufacturing lead time (from typically 6 months to 10 days $^{20}$ ) and to improve sustainability by reducing waste generation. ${ }^{21}$ This is taking place, in part, as a response to initiatives promoted by the United States Food and Drug Administration (FDA) which in 2003 began to encourage the industry to develop new, innovative processing methods to improve product consistency. ${ }^{22-24}$

Innovations have been reported to transition synthesis, crystallization, and secondary processes from batch to continuous operations. However, both API and intermediate isolations are still almost exclusively performed batch wise. There have been few attempts to develop equipment to address the gap of continuous pharmaceutical isolation. ${ }^{25-29}$ and the strategies to transition from batch to continuous API isolation are not well investigated.

In this work, strategies for the development of an API isolation process in batch mode using a screening DoE approach are investigated before the knowledge gathered is used to operation in a semicontinuous mode. A d-optimal design of experiments (DoEs) was used to investigate this multivariate problem, containing both qualitative and quantitative factors, in order to minimize the number of experiments required to characterize the system. Usually in industry the isolation strategy is developed batchwise using Nutsche filters, while continuous isolation is conducted with other isolation systems (rotary drum, belt filter, etc.). Changing the isolation equipment increases the challenges related to the process conversion from batch to continuous. Therefore, scientists need not only consider aspects like isolation chamber size variation but also variation of the isolation mechanism. In this study, the use of a single unit capable of the isolating material in a batch and semicontinuous/ continuous way, the CFD25 (Alconbury Weston Ltd, AWL, $\mathrm{UK}),{ }^{30}$ has been used to investigate how easily the batch isolation strategy development can be transferred to the CFD25 semicontinuous isolation approach. An isolation strategy was developed using the CFD25 in batch mode (called optimization mode) and then used virtually unchanged to run the CFD25 in a semicontinuous/continuous manner (production mode).

Common practice in filter cake washing is to use at least three cake volumes of the wash solvent to remove mother liquor and the associated impurities of synthesis. This typically amounts to 5 to $7 \mathrm{~mL}$ of solvent per gram of API produced. ${ }^{31}$ The goals of this work are the following:

- To improve washing efficiency and consequently minimize solvent use;

- To improve environmental sustainability in API isolation minimizing solvent consumed;

- To improve product purity;

- To reduce manufacturing costs.

The main target of continuous isolation is to reduce the processing time and cost ${ }^{31}$ whilst minimizing negative impacts on API particle physical properties in order to deliver API that is optimal for final processing into drug products, for example, eliminating the need for a particle size reduction step after isolation. $^{32}$
The effect of input slurry properties such as solid loading, PSD, and crystallization solvent were investigated to determine their impact on the filtration and washing performance and the characteristics of the dry isolated product. Two different PSD grades of API were used, a typical crystalline product, and micronized paracetamol. Paracetamol was selected as model compound because it is a well-researched compound and is thereby facilitating experimental work; ${ }^{20,22,23}$ also, the majority of its related impurities are commercially available. The role of washing was explored by analyzing the effect of different crystallization and wash solvents and the quantity of wash solvent used to remove paracetamol related impurities such as acetanilide and metacetamol because of their different solubility respect to the paracetamol in crystallization and in the wash solvent. Acetanilide does not contain in the molecular structure the hydroxyl group that reduce solubility in solvents, whereas metacetamol is the meta isomer of paracetamol showing lower solubility respect to the paracetamol. The slurries used were generated from pure materials, where the related impurities were dissolved in the crystallization solvent to mimic slurries produced during a crystallization process. Product crystal suspensions were prepared using three potential crystallization solvents: ethanol, isopropanol, and isoamyl alcohol. ${ }^{33-35}$ Three different wash solvents were evaluated. $n$-Heptane and isopropyl acetate were selected based on their miscibility with the primary crystallization solvents to facilitate diffusional and dilution washing mechanisms and therefore facilitate impurity removal; isopropyl acetate and $n$-heptane exhibit relatively high and very low paracetamol solubility, respectively. The third wash solvent $n$-dodecane was selected as an immiscible wash solvent to exemplify displacement washing in the absence of miscibility. In each case, the wash strategy was designed to minimize the nucleation of new crystals during washing.

Industrial practice is to follow the International Conference of Harmonisation ( $\mathrm{ICH}$ ) harmonised tripartite guideline Q6A (test procedure and acceptance criteria for new substances and new drug products) to identify the tests required to analyze drugs and drug products to evaluate the product conformance to specifications. As described in ICH Q6A guideline, ${ }^{36}$ a series of tests are required during the design and development of a new product/process, these include the following:

- Identification and assay test, such as HPLC, to verify paracetamol compound content with respect to the relative impurities

- PSD tests

- A series of specific tests to verify the impact of specific product properties on the downstream process.

The analytical strategy proposed covers a series of analytical characterizations to determine filtration properties ${ }^{37}$ (specific test), residual solvent content and composition after drying (specific test), purity achieved during washing of the isolated material, PSD, and agglomeration propensity, and strength of the isolated product (specific test) here used is following the industrial practice and the ICH guideline specifications.

Filter cake properties were determined using the on-board machine vision system in the CFD25 to halt filtration at dryland $^{a}$ and to record filtration rate data. The filter cake and filtrate were both analyzed using HPLC to quantify the purification achieved. The mechanical properties of the isolated product were evaluated; the extent of agglomeration, the agglomerate PSD, and the agglomerate mechanical strength were all measured. Proton nuclear magnetic spectroscopy $\left({ }^{1} \mathrm{H}\right.$ 
NMR) was used to determine the residual solvent in the dried filter cake.

The isolation strategy developed during the screening DoE was used to run a semicontinuous isolation test. The samples collected were analyzed using the same analytical procedure to determine filtration properties, residual solvent content and composition, isolated cake purity, extent and PSD, and strength of agglomerates.

\section{MATERIALS AND METHODS}

2.1. Materials. Two PSD grades of paracetamol (typical crystalline and micronized) were selected to challenge different aspects of filtration, washing, and drying. The micronized material (Mallinckrodt, Inc., batch 042213E407: $x_{50}, 24.55 \mu \mathrm{m}$; SMD, $18.66 \mu \mathrm{m}$ ) settles slowly and filters slowly, has a large wetted surface area to wash, and is more challenging to dry than the granular grade material. The intermediate powder grade was used to mimic a typical crystalline material (Mallinckrodt Inc., UK, batch 637514D001: $x_{50}, 64.03 \mu \mathrm{m}$; SMD, $46.35 \mu \mathrm{m}$ ). The PSD of the two different materials are reported in the Supporting Information section.

Two structurally related compounds of paracetamol were used, acetanilide and metacetamol; if present at the end of the synthesis, they could affect the crystallization process. ${ }^{33,34,38}$ HPLC was used to determine purity of the isolated product. The eluents contained water (Water, Ultrapure, HPLC Grade, Alfa Aesar) and methanol (Methanol, Ultrapure, HPLC Grade, $99.8+\%$, Alfa Aesar); the methanol was also used as diluent for some samples. Dimethyl sulphoxide- $d$ (extent of deuteration $99.8 \%$ for NMR spectroscopy, VWR, UK) was used as the NMR solvent.

To investigate efficiency of the AWL's CFD25 to isolate a "real process slurry" a series of three crystallization solvents were used: ethanol [purity $\geq 99.8 \%$ (GC), from Sigma-Aldrich], propan-2-ol (IPA) [purity $\geq 99.5 \%$ (GC), from Sigma-Aldrich], and 3-methylbutan-1-ol, (known as isoamyl alcohol) [purity $\geq$ 99.5\% (GC), from Sigma-Aldrich. As for the wash solvents, $n$ heptane (purity 99\% from Alfa Aesar, UK), isopropyl acetate (purity 99+ \% from Alfa Aesar), and $n$-dodecane (purity 99\%, from Alfa Aesar) were selected. The washing approach used for each crystallization-wash solvent combination is reported in the Results and Discussion section.

2.2. Raw Material Characterization. A series of raw material characterization were conducted to investigate the following:

- The PSD of the paracetamol material used to generate the slurry. The PSD of micronized and typical crystalline material were determined by image analysis (QICPIC particle size analysis, Sympatec, Germany, QICPIC Rodos/L; trigger conditions: feed pressure 1 bar, VIBRI feeder, feed rate $25 \%$, gap width $1.5 \mathrm{~mm}$ ).

- The solubility of paracetamol in the crystallization and wash solvents was determined experimentally by equilibration and gravimetric analysis using an incubator (Incubator S160D, Stuart, Cole-Parmer, UK) on a multiposition stirrer plate. The measured values were compared with those taken from the literature, ${ }^{39,40}$ where available, and values were predicted using COSMOTherm (COSMOlogic GmbH \& Co. KG, Germany).

- The true density of the paracetamol grades was determined with the Accupyc 1330 V1.30 Helium pycnometer. Ten replicas for each compound were run.
Specific surface area BET $\left(\mathrm{m}^{2} / \mathrm{g}\right)$ using octane as the vapor probe.

- The impurity content in the filter cake and filtrate. Calibration curves for pure paracetamol, acetanilide, metacetamol, and orthocetamol (an impurity present in the raw paracetamol) were gathered using a multilevel calibration method. An Agilent 1260 Infinity II system with a diode array and RI detector was used. The column was an Agilent Poroshell 120 EC-C18 $4.6 \times 100 \mathrm{~mm} \times 4$ $\mu \mathrm{m}$ operated at $40^{\circ} \mathrm{C}$, with a flow rate of $1 \mathrm{~mL} / \mathrm{min}$. The injection volume was $5 \mu \mathrm{L}$, wavelength: 243 and 230.5 $\mathrm{nm}$, the mobile phase was $80 \%$ water and $20 \%$ methanol.

- The compressibility index of the two PSD grades was determined by filtering three different aliquots of slurry using three different pressure driving forces: 300, 500 and 900 mbar. The natural logarithm of the cake resistances measured during these experiments is plotted against the natural logarithm of the driving force, and the slope of the linear fitting is giving the cake compressibility. ${ }^{3}$

- The potential for "antisolvent effects" to occur during washing. A fast screening procedure to identify appropriate crystallization-wash solvent mixture compositions was conducted. This test is performed to minimize paracetamol dissolution, whilst avoiding precipitation of fine paracetamol particles or impurities. The potential for particle formation during washing from a thermodynamic perspective can be estimated relatively rapidly from solubility data, whereas the kinetics needs to be determined experimentally by a more time consuming process. This screening method is rapid and simple to operate, allowing the experimentalist to determine whether the kinetics of particle formation due to washing are comparable with the washing step or if the "antisolvent effect" is taking longer time to occur. For all the combinations of crystallization and wash solvents screening was conducted at room temperature by contacting paracetamol saturated primary solvent, which mimiced the mother liquor, with each wash solvent. Different ratio of the solvent pairings were analyzed: $50-50,40-60,30-$ $70,20-80,10-90$ and $100 \%$ pure wash solvent. For the combination of isopropanol and dodecane, $60 \%$ crystallization and $40 \%$ of wash solvent was also tested. Compositions which resulted in product being precipitated were rejected.

2.3. Slurry Preparation: Test CFD25 with Structurally Related Paracetamol Compounds. Suspensions containing dissolved acetanilide and metacetamol the representative impurities of synthesis were prepared as a concentration of $2 \%$ by mass of each impurity. The required mass of each impurity was weighed and dissolved fully in the crystallization solvent prior to adding any paracetamol. The amount of paracetamol required to saturate the solvent solution was then added and dissolved. The last step in suspension preparation was to add the paracetamol required to form the cake, this paracetamol represents the solid load, calculated in \% by mass. This twostage addition of paracetamol was crucial to avoid partial dissolution of the cake forming particles affecting the filter cake properties.

To avoid "antisolvent effect" leading to dissolved API being precipitated during the first wash step the first stage wash was prepared using a mixture of pure crystallization and wash solvents. The composition was selected based on the wash 
solvent screening methodology outlined in the Raw Materials Characterization section. The second washing step was conducted using pure wash solvent. In each instance, the wash solvent quantity was based on the cake void volume and the criteria set up in the experimental design.

2.4. CFD25 Continuous Filtration, Washing and Drying System Overview. The CFD $25^{b 41}$ is a dead end filtration unit able to filter, wash and dry API cakes in manual, semiautomated or even semicontinuous mode (Figure 1). It is an advanced

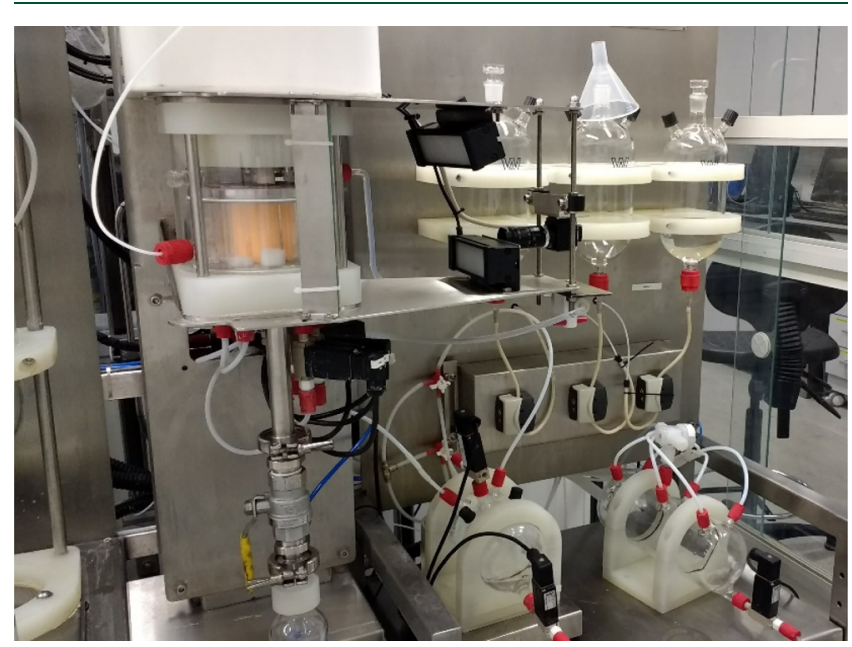

Figure 1. CFD25 carousel filtration and isolation unit.

prototype which was developed to allow the investigations reported here to take place and to use the data gathered to further enhance the operability of the final product. ${ }^{42}$

The prototype unit is controlled through a touch-screen panel. The unit consists of:

- A slurry tank with agitator to provide a homogeneous slurry. This vessel has two functions: (1) holding a set volume of API for a trial, (2) buffer vessel to be placed between a continuous crystallizer/reactor and the continuous filter dryer to allow for planned and nonplanned upstream downtime.

- A vacuum transfer system is used to intermittently withdraw aliquots of slurry from the slurry vessel to the charge vessel, before then discharging the aliquot under gravity into port 1 of the isolation carousel. The transfer system is described in Section 2.4.1.
- The carousel consists of 10 different glass tubes of 22.4 $\mathrm{mm}$ diameter where filtration, multiple washing stages, deliquoring and drying is carried out. These tubes rotate above a base with ten apertures, nine of which contain a BOPP Poremet $20 \mu \mathrm{m}$ filter mesh (G. BOPP \& CO.). The filter chambers are formed when the carousel is compressed against the base plate with each glass tube located above a filter. Position 1 of the carousel is used for slurry feeding and filtration, position two and three can be used for multiple washing steps position four can be used for additional washing or deliquoring step, while positions five to nine are used for drying. There is no filter media present in position 10 which allows the cake to be mechanically ejected by a pneumatic cylinder (Figure 2).

- Two wash solvent containers are connected to the washing positions. To prevent disturbance of the cake surface, wash solvent is dispensed on top of the cake using atomization nozzles.

- A receiver is connected to the bottom of each carousel position allowing the user to collect the liquid phase, remove and analyze the impurity content in each filtrate phase, or to evaluate filtrate removed in each filtration/ wash/drying stage.

- Static drying is carried out under vacuum to allow the flow of ambient or heated compressed air to flow through the cake. The temperature of the gas is controlled by the onboard electronics to ensure that the temperature sensitive compounds are not damaged. To heat up the gas, a system invented by Purdue University and developed by AWL is used. ${ }^{42}$ The C-Core carbon heated transfer line is composed of a woven carbon fiber tube covering a PTFE transfer tube. A voltage is applied to the carbon fiber which then reaches the desired temperature in seconds. This in turn heats up the transfer tube and therefore the drying gas. This technology ensures flexible and accurate control of the temperature of the drying gas delivered to the drying port.

Please note, drying times are generally longer than the process time in a filtration or washing port. Drying in one port position would extend the cycle time and therefore decrease overall throughput. This decrease in throughput is overcome in AWL's filter dryers by sharing the drying across 5 drying port positions. This means that the drying time can be 5 times the time of the filtration/washing port position with the longest processing time. In terms of throughput, the limiting factor can be related to either the processing time required for all filtration and washing

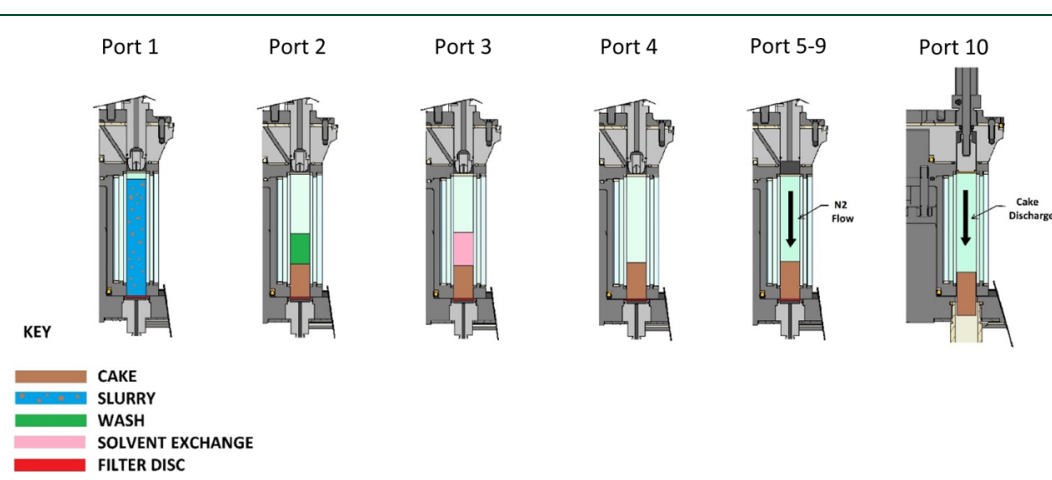

Figure 2. CFD25 schematic operative procedure. From left to right: port 1 where the suspension is fed and filtered; port 2, where cake is washed the first time; port 3 , where cake is washed a second time; port 4, where cake is deliquored; port 5 , where convective drying (in optimization mode) is done. In production mode drying is subdivided from port 5 to 9 . Port 10 is used to discharge the dried cake. 


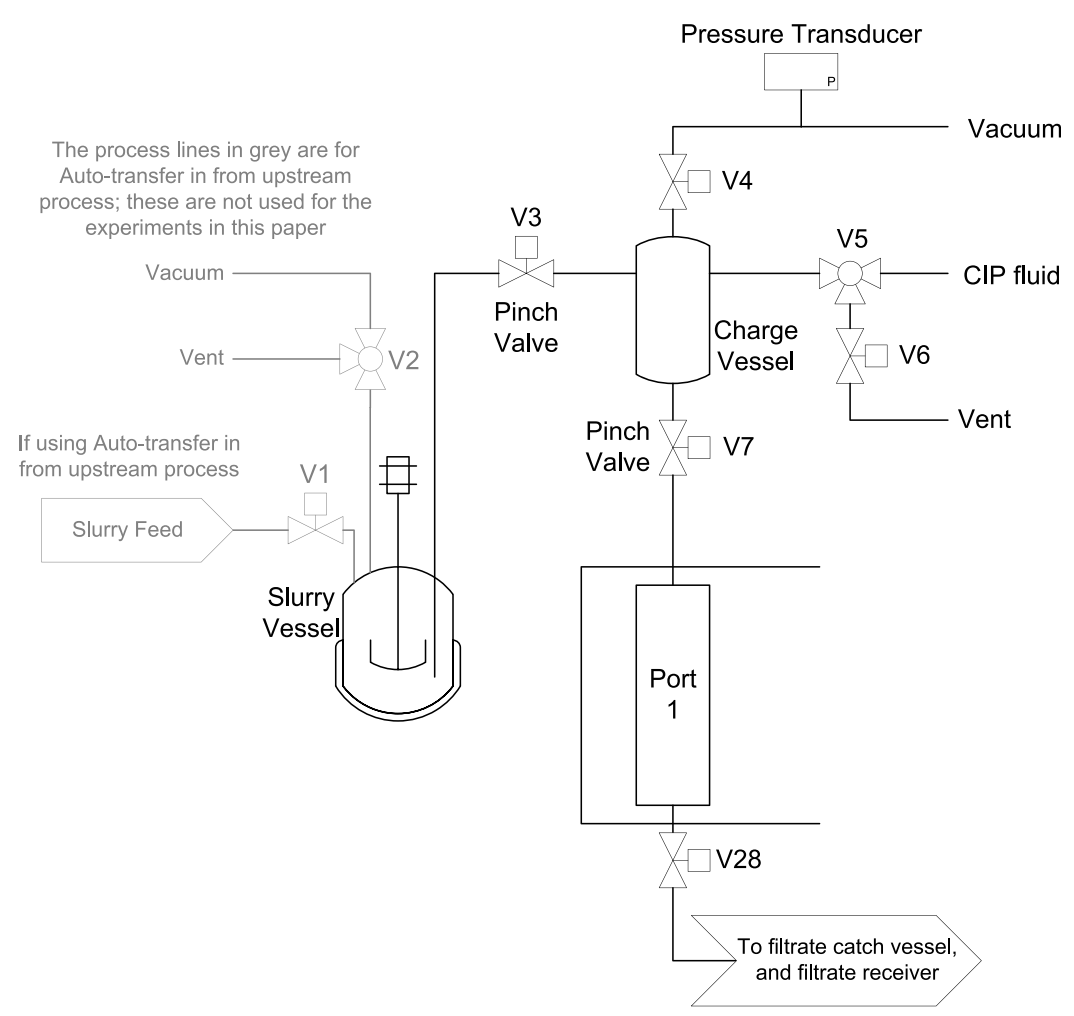

Figure 3. Process diagram of slurry transfer system for transferring aliquots of slurry from the slurry vessel to the charge vessel using a vacuum, before discharging the aliquot under gravity into port 1 of the isolation carousel.

(a)

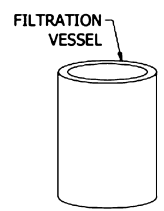

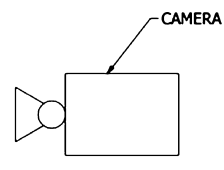

(b)

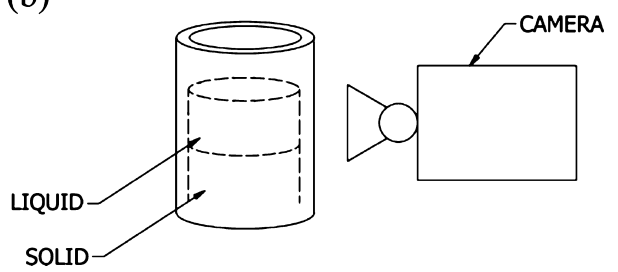

Figure 4. Schematic of the camera arrangement for the vision system. (a) The camera looks through the side of the glass tube (filtration vessel). (b) The liquid and solid interfaces are visible to the camera.

steps, or the time required for drying. In the CFD25, the drying time per port can be specified, the system can therefore be dried for the specified time regardless of the total time required for filtration and washing. If extended drying times are required to achieve specified moisture levels then overall throughput will be effected. For a production unit which processes material requiring a long drying period, the number of drying ports can be increased to increase the drying time.

2.4.1. Slurry Transfer System. The slurry transfer system is illustrated in Figure 3. The transfer line between the slurry vessel and the charge vessel consists of the following; a PTFE lined stainless steel $6 \mathrm{~mm}$ ID dip tube with a length of $300 \mathrm{~mm}$, a $4 \mathrm{~mm}$ ID transfer line with a length of $1 \mathrm{~m}$, and a pneumatic pinch valve (V3) with $10 \mathrm{~mm}$ ID. The line between the charge vessel and the isolation carousel consists of a pneumatic pinch valve (V7) with $10 \mathrm{~mm} \mathrm{ID}$ and an $8 \mathrm{~mm}$ ID tube with a length of $150 \mathrm{~mm}$.

The vacuum transfer procedure is carried out as follows: (1) a specified level of vacuum is created in the charge vessel, (2) the pinch valve between the slurry vessel and charge vessel is opened and an aliquot of slurry is drawn into the charge vessel, (3) the pinch valve between the slurry vessel and charge vessel is then closed, (4) the pinch valve between the charge vessel and isolation carousel opens and the aliquot of slurry is transferred under gravity into the first port position of the carousel, (5) the pinch valve between the slurry vessel and charge vessel opens, allowing any residual slurry/solids in the transfer line to fall back into the slurry vessel.

To ensure that a representative sample of slurry is drawn from the slurry vessel, the slurry vessel agitator is rotated at a speed which fully suspends the solids, and the end of the dip tube is placed toward the bottom of the vessel in a well-agitated region, approximately $1 \mathrm{~cm}$ from the agitator. The level of slurry is kept above at least $300 \mathrm{~mL}$ to ensure that the solids were suspended in a reasonable volume of slurry. Preliminary experiments used the camera to measure the volume of the aliquot and the volume of solids in that aliquot. The variation in the \% solids was $\pm 9 \%$ measured across 6 number of samples.

To ensure that a consistent volume of slurry is transferred for each aliquot, the vacuum transfer system is calibrated. The volume of slurry carried into the charge vessel is controlled by vacuum levels measured in the charge vessel. The vacuum level required to draw over a small volume dose (e.g., $25 \mathrm{~mL}$ ) and the vacuum level required to draw over a large volume dose (e.g., 75 $\mathrm{mL}$ ) are recorded. The system uses these vacuum values to plot a 
graph of vacuum level versus volume transferred. The system uses this plot to calculate the vacuum level required to draw over a specified volume. The accuracy of the slurry volume transfer is $\pm 2 \mathrm{~mL}$.

The volume transferred into the ports of the isolation carousel are measured by the camera vision system, as shown in Figure 3 and described in more detail in Section 2.4.2.

2.4.2. Vision System. The CFD25 employs a vision system to determine the relative heights of the liquid phase and accumulated solids (Figure 4). The camera measures the position of the meniscus of the liquid and the height of the cake by detecting dark-to-light (or light-to-dark) transitions. The camera measures pixel values which are then converted into volumes in milliliters. Before the camera is used to measure volumes, the camera is calibrated by placing calibration sticks of known height and volume within the ports of the isolation carousel. The system records the pixel values of the top of the calibration stick and uses these values to convert pixel values into volumes for each port position.

There are two different modes: one for a slurry with solids which settle within a reasonable time (i.e., a "settling slurry") and one for a slurry with solids that do not settle in a reasonable time and/or when the level of the cake cannot be detected by the camera.

For a slurry with solids that settle within a reasonable time (a "settling slurry"), the vision system can detect the meniscus of the liquid and the level of the solid due to dark-to-light transitions. This allows filtration and washing to be stopped at dry land or allowed to continue to breakthrough by bypassing the automatic control and stopping the filtration manually. Halting the process at dry land when the liquid interface reaches the cake surface ensures that the cake remains fully saturated and establishes ideal conditions for displacement washing. To allow a partial separation of liquid and solid phases and guarantee the ability of the vision system to work, after slurry charging and before filtration in port 1 , slurry is maintained undisturbed for a few seconds. The liquid level is tracked while the filtrate is being removed; this approach allows the recording of the filtrate volume removed during the time. This consequently allows for the calculation of filtration parameters such as filtrate flow rate, cake and media resistance, cake permeability, cake volume, and cake density. Cake compressibility can be measured during the optimization mode, by filtering different aliquots of slurry at different driving forces and comparing the cake resistance generated.

For a slurry with solids which do not settle easily (a "nonsettling slurry") or a slurry which deposits significant quantities of particles on the walls of the tube, a "non-settling mode" can be selected which uses an expected cake height. An automated calibration procedure has been developed to calibrate the expected cake height. The calibration procedure first draws over a specified volume of slurry into port 1 and measures the volume of slurry transferred. The slurry in port 1 is then filtered. Once the operator sees that the cake is deliquored, the operator can accept the measured cake height of the deliquored cake. The system then draws over another aliquot of slurry with a different specified volume. The slurry is filtered, the cake is deliquored, and the cake height is accepted by the user and recorded. The system plots the "expected cake height" versus "measured slurry volume" based on the two points that have been recorded. The system can therefore use this plot to calculate the expected cake height from the measured slurry volume during optimization or production mode. A tolerance band of a few $\mathrm{mL}$ can be specified so that the filtration can be stopped before reaching the expected cake height.

There may be cases where the slurry or wash solvent splashes the wall of the tube. This may cause the camera to briefly detect the splashes as a light-to-dark transition, therefore incorrectly measuring this splash as the liquid level. Improvements that have been made to the vision software to prevent this are described in Section 3.2.1.

There may be cases where the slurry splashes the walls of the tube. This may cause the camera to briefly detect the splashes as a light-to-dark transition, therefore incorrectly measuring this splash as the liquid level. To prevent this, if the liquid level detected by the camera momentarily jumps to another position, the software will ignore this and continue to measure the true liquid level.

Post-filtration in port 1 , a slurry is yet to be encountered which cannot be removed from the walls with wash solvent dispensed through the spray nozzles. This allows the camera to operate using the same settings for ports 2-4 irrespective of slurry attributes.

In cases where halting filtration before breakthrough, or where the user doesn't require the automatic capture of filtration data, there are other systems available from AWL without the transparent carousel and therefore no vision system. For systems without the vision system, the filtration and washing control are based on pump times and vacuum times.

2.4.3. Modes of Operation. Three different operating approaches can be used: fully manual, semiautomated, called "Optimization Mode", and fully semicontinuous, called "Production Mode". Manual mode is used when the operator requires full control of each step of isolation; this method uses the maximum available vacuum ( $900 \mathrm{mbar}$ ) to filter the cake and as the camera cannot be used to halt filtration at dry land, the operator must manually stop the filtration step. In addition, the operator may manually control wash quantity, wash solvent deliquoring, and drying.

Optimization mode is when a single cake progresses through each of the various carousel stations with the exception of the drying stage which is carried out solely in port 5: this mode is recommended for process development as it can generate the maximum data from the minimum product and it allows for the collection of filtrate and wash solvent from each port for off-line analysis. To set filtration, washing, and drying parameters, a setup screen is used to program the unit. After a single cake has been processed, it is possible to wash the filter plates with a washin-place (WIP) solvent. When using optimization mode for the experiments in this paper, $25-30 \mathrm{~mL}$ of acetone was drawn through each filter plate in ports $1-4$, before the next aliquot of slurry was processed.

Production mode is fully automated and can simultaneously process a cake in each port and so isolate multiple aliquots of slurry: this mode uses the filtration parameters obtained in optimization mode and allows for maximum throughput. To allow semicontinuous cake processing, drying is divided through ports five to nine.

2.4.3.1. Production Mode in CFD25. The production mode set for this work consisted on a series of operations:

- Transfer from the slurry tank to port $1,65 \mathrm{~mL}$ of slurry; cake and filtrate volume were semicontinuously recorded by the camera; filtration was stopped at dryland (i.e., when the liquid level reached the top level of the cake); 
Table 1. DoE Factors and Responses Selected to Investigate a Multivariable Problem

\begin{tabular}{|c|c|c|c|c|}
\hline & \multicolumn{4}{|c|}{ factors } \\
\hline & abbreviation & units & type & settings \\
\hline \multirow{7}{*}{$\begin{array}{l}\text { API solid load } \\
\text { PSD (grade) } \\
\text { isolation pressure } \\
\text { crystallization solvent } \\
\text { wash solvent } \\
\text { volume of wash solvent }{ }^{a} \\
\text { drying time }\end{array}$} & API & $\mathrm{w} / \mathrm{w}(\%)$ & quantitative & $15-25$ \\
\hline & PSD & & qualitative & micronized, powder \\
\hline & FP & mbar & quantitative & $200-800$ \\
\hline & Crys & & qualitative & ethanol, isopropanol, isoamyl alcohol \\
\hline & wash & & qualitative & $n$-heptane, dodecane, isopropyl acetate \\
\hline & WV & volume ratio relative to cake volume & quantitative & $2-4$ \\
\hline & dry & s & quantitative & $180-600$ \\
\hline \multicolumn{5}{|c|}{ responses } \\
\hline \multicolumn{3}{|c|}{ cake volume after first filtration } & & $\mathrm{mL}$ \\
\hline \multicolumn{3}{|c|}{ first filtration flow rate } & & $\mathrm{mL} / \mathrm{s}$ \\
\hline \multicolumn{3}{|c|}{ cake resistance } & & $\mathrm{m} / \mathrm{kg}$ \\
\hline \multicolumn{3}{|c|}{ medium resistance } & & $1 / \mathrm{m}$ \\
\hline \multicolumn{3}{|l|}{$x_{50}$} & & $\mu \mathrm{m}$ \\
\hline \multicolumn{3}{|c|}{ mean diameter (xsv) } & & $\mu \mathrm{m}$ \\
\hline \multicolumn{3}{|l|}{ LOD } & & $\%$ \\
\hline \multicolumn{3}{|c|}{ percentage wash solvent in dried cake } & & $\%$ \\
\hline \multicolumn{3}{|c|}{ percentage crystallization solvent in dried cake } & & $\%$ \\
\hline \multicolumn{3}{|c|}{ extent of agglomeration } & & $\%$ \\
\hline \multicolumn{3}{|c|}{ ABI index } & & ratio \\
\hline \multicolumn{3}{|c|}{ first filtrate: metacetamol, orthocetamol, and acetanilide concentration } & & $\mu \mathrm{g} / \mathrm{mL}$ \\
\hline \multicolumn{3}{|c|}{ second filtrate: metacetamol, orthocetamol, and acetanilide concentration } & & $\mu \mathrm{g} / \mathrm{mL}$ \\
\hline \multicolumn{3}{|c|}{ third filtrate: metacetamol, orthocetamol, and acetanilide concentration } & & $\mu \mathrm{g} / \mathrm{mL}$ \\
\hline \multicolumn{3}{|c|}{ cake metacetamol, orthocetamol, and acetanilide concentration } & & $\mu \mathrm{g} / \mathrm{mL}$ \\
\hline
\end{tabular}

${ }^{a}$ Wash solvent volume was automatically calculated by the camera vision software. Knowing the tapped density of paracetamol and cake volume after the filtration, the volume of wash solvent added corresponded to 1,2 , or 3 void volumes in the cake. Tapped density of micronized paracetamol corresponded to $0.46 \mathrm{~g} / \mathrm{mL}$, while typically crystalline (named also powder) corresponded to $0.44 \mathrm{~g} / \mathrm{mL}$.

the head of the carousel lifted allowing the carousel to rotate one position to index the cake from port 1 to port 2 .

- The camera automatically calculated the volume of wash solvent required to wash the cake in port 2 in relation to the cake volume and cake void fraction; the volume of wash solvent was set in the setup mode, corresponding to 1 cake void volume. The solvent selected as wash 1 was a mixture of ethanol-heptane $(50-50 \% \mathrm{v} / \mathrm{v})$, used to prevent antisolvent effect during washing. The wash solvent was pumped into port 2 . Concurrently in port 1 , another dose of slurry was dispensed. When the slurry was fully dispensed in port 1 , vacuum was applied in ports 1 and 2, and filtration (port 1) and washing (port 2) proceeded simultaneously. Filtration and washing both stopped at dry land by the automatic operation of individual bottom outlet valves. Upon completion of the filtration and washing processes, the carousel head lifted and the cakes indexed to port 3 and 2

- Three corresponding cake void volumes of wash solvent 2 (n-heptane) was automatically measured and dispensed in port 3 whilst wash solvent 1 was measured and dispensed in port 2 and $65 \mathrm{~mL}$ of slurry were transferred in port 1 . As above, vacuum was then applied and in each port, filtration stopped at dry land. The carousel again indexed one position moving the cakes to ports 4,3 , and 2 .

- In port 4 , the cake saturated with $n$-heptane (from wash 2 ) was deliquored for $20 \mathrm{~s}$ whilst all other process described in the step above were repeated.

- Ports 5 to 9 were each used as a drying station: each station dried the cake for $30 \mathrm{~s}$; ambient temperature gas $\left(25^{\circ} \mathrm{C}\right)$ was split into those 5 ports. The unit is also able to dry the wet cake at different drying temperatures; however, for this test, drying temperature was considered a fixed parameter.

- Port 10 was used to eject the cake.

In cases where filtration and/or washing is protracted due to incorrect detection of cake and liquid levels, the process in each port was set to stop after a defined period ( $800 \mathrm{~s}$ for filtration and $300 \mathrm{~s}$ for washing, with a further constraint of a maximum process time of $999 \mathrm{~s}$ ). When these time limits are reached, the unit proceeds to index to the next stage, regardless of the residual solvent mass left behind so that processing can continue.

To avoid filter blinding, a WIP process was completed every 5 indexes in ports $1,2,3$, and 4 . Some preliminary tests showed that acetone was a suitable WIP solvent for this process. The WIP sequence dispenses $25-30 \mathrm{~mL}$ of WIP solvent through each of the filter plates in ports $1-4$. The WIP sequence is as follows:

1. Ports $2-10$ continue as normal but no slurry is dosed into port 1 . Once all ports have completed the carousel indexes one position

2. Ports $3-10$ continue as normal. Port 2 does nothing and is complete. Port 1 is dosed with a volume of WIP solvent. The solvent sits on the filter plate for a specified time to allow the fines to be dissolved before a vacuum is then applied under the plate to draw the WIP solvent through. Once all ports have completed, the carousel indexes one position.

3. Ports $4-10$ continue as normal. Port 1 and 3 do nothing and are marked as complete. Port 2's filter plate is washed with a WIP solvent as described above. Once all ports are complete, then the carousel indexes one position. 
4. Ports 1 and 5-10 continue as normal (i.e., slurry is dispensed and filtered in port 1 , and ports 5-10 continue as normal). Ports 2 and 4 do nothing and are marked as complete. Port 3's filter plate is washed as described above. Once all ports are complete then the carousel indexes one position.

The same procedure is repeated until port positions $1-4$ have been washed with WIP solvent.

2.5. Experimental Design: CFD25 with Paracetamol and Related Compounds. A DoE approach was used to analyze a multifactorial problem minimizing the number of experiments to run and to maximize the number of achievable results. MODDE was selected as software for the DoE data analysis. The model used to analyze the data is a screening $\mathrm{d}$ optimal process model where seven factors and seven responses were selected. A total of 21 experiments were run. The d-optimal approach is appropriate in this case because the experimental variables investigated comprise of a combination of quantitative and qualitative factors. ${ }^{55,56}$ The seven factors selected were a combination of three qualitative and four quantitative factors. Factors, factor ranges, and responses are reported in Table 1. Three center points were used for the design space, and no constraints or inclusions were set. Three factors were selected for the design space: API solid load, isolation pressure (driving force), and volume of wash solvent. Anova data analysis was not used for this DoE because this data analysis approach is valid only in case of DoEs presenting only quantitative factors. A PLS fitting model was used to determine the correlation between factors and responses. This fitting model is used in case several responses were measured, and the model is used to simultaneously represent the variation of all the responses in response to the variation of the factors. Table 1 describes the list of quantitative and qualitative factors and the responses generated. These factors and responses were selected to investigate the effect of solid load, raw material PSD, crystallization and wash solvent selection, wash solvent volume and drying time on final dried product purity, PSD, and moisture content.

In the Results and Discussions section, the correlation between factors and responses are reported using the coefficient plots. The coefficient plots provide graphical representation of the significance of the model terms in explaining each experimentally determined response. A significant term is one with a large distance from $y=0$ as well as having an uncertainty level that does not extend across $y=0$. A nonsignificant model term is a model term close to $y=0$ and with an uncertainty level that crosses $y=0$ ". The error bar expresses the $95 \%$ confidence interval that is related to the coefficient. Some of the regression coefficient plot presented in the Results and Discussions section reports on the $Y$ axis (responses) and presents the expression "extended". If a term in the model comprises a qualitative factor, $C$, with $k$ levels, there will be $k-1$ expanded terms associated with that term for the regular option, whereas in the expanded option all of the levels are correlated with the selected response. For example considering the crystallization solvent as a qualitative factor, there are three levels, ethanol, isopropanol, and isoamyl alcohol. In the regular option for presenting the qualitative coefficients, MODDE is plotting isopropanol and isoamyl alcohol, while the expanded option is plotting all of the three levels.

The effect plots and experimental evidences observed during this work were used together to qualitative define the optimal batch isolation design space to be transfer to the semicontinuous experiment. The combination of qualitative and quantitative factors used in this screening DOE does not allow the prediction of the optimal design space. However, the use of qualitative factors was needed to screen essential isolation parameters.

2.6. Offline Filtrate and Cake Characterization Techniques. Offline sample characterization followed a precise sequence to prevent destruction of material required for further characterization:

- Cake resistance and media resistance $e^{10-12}$ and filtration flow rate. Data were collected using the on-board vision system software. Cake and filtrate masses were weighed at the end of each batch experiment.

- To determine how effectively the residual solvent had been removed, around $40 \mathrm{mg}$ of "wet" filter cake was collected at the end of the allocated drying time to determine the total residual solvent and to quantify individual solvent residues (percentage of crystallization and wash solvent). An AVII+600 NMR spectrometer BRUKER ADVANCE 2+ (Bruker, UK) was used to collect proton NMR spectra. The sample collection procedure was designed to gather a representative sample of the wet product cake which once collected was dissolved in $0.75 \mathrm{~mL}$ of DMSO- $d$. To determine number of scansions, a $\mathrm{T} 1 / \mathrm{T} 2$ relaxation time evaluation was performed for all of the solvent combination (process parameters: frequency axis F1 equals to 32 , pulse program t1ir, 4 scans, 2 replicas of T1/T2 analysis to evaluate T1 relaxation). Samples were analyzed using 64 scans, corresponding to approximately 5 times $\mathrm{T} 1$. The time determined from the $\mathrm{T} 1 / \mathrm{T} 2$ relaxation time test (5T1) was required to maximize peak to noise intensity and also to detect very small quantity of proton signals from traces of solvents. Each sample was analyzed in duplicate.

- Cakes were dried to stable mass in a vacuum oven (Gallenkamp, UK) at $50{ }^{\circ} \mathrm{C}$ and $20 \mathrm{mbar}$ of reduced pressure to determine the moisture content (loss on drying, LOD \%).

- The acetanilide and metacetamol contents in filtrates and cake were determined using HPLC; no filtrate assay was done during the semicontinuous run. The reason for this is due to impractical implications. There are catch bottles located underneath ports 1 to 5 used to separately collect the filtrate from each stage during optimization mode. In production mode, the cakes are being processed simultaneously; therefore, the filtrate from the first cake is then mixed with the filtrate of the second cake, and the wash from the first cake would mix with the wash from the second cake, etc. It is possible for the operator to track the position of a cake and change the bottles underneath each port to collect the filtrate and wash separately for one cake and prevent mixing filtrate with filtrate from another cake. However, this would require removing and replacing numerous bottles simultaneously. This would also require the unit to be paused affecting the throughput and alter the wash solvent contact time, therefore potentially capturing mis-representative data. The new systems may include extra valves and software in order to collect filtrate/wash samples from a cake at certain intervals during a production run without the need to pause the unit. 
- The extent and strength of agglomerates were measured with a methodology proposed by Birch and Marziano's. ${ }^{7}$ The extent of agglomeration was determined by measuring the mass of material retained by a $1 \mathrm{~mm}$ sieve (Endecotts Ltd). The sieves were shaken by hand to avoid particle breakage. The extent of agglomeration was calculated as the mass ratio of the mass of agglomerates larger than $1 \mathrm{~mm}$ and the total sample mass. The strength of agglomerates, also defined as friability or ABI index, was measured by transferring the product particles to a sieve stack comprising of $1 \mathrm{~mm}, 500,250$, and $180 \mu \mathrm{m}$ sieves. The sieve column was shaken for $180 \mathrm{~s}$ using a vortex shaker. Next, the mass of fraction retained on each sieve was determined. This process of vortexing and weighing was repeated to allow the extent of agglomeration and agglomerate brittleness index ( $\mathrm{ABI}$ ) for each cake to be measured and calculated in accordance to Birch and Marziano's ${ }^{7}$ approach, with every lump of particles bigger than $1 \mathrm{~mm}$ size being considered an agglomerate.

- The PSD of dried cake particles smaller than $1 \mathrm{~mm}$ was measured using the same method used for the PSD raw paracetamol characterization.

\section{RESULTS AND DISCUSSIONS}

3.1. Development of Batch Isolation Strategy. 3.1.1. Antisolvent Effect Screening. In Table 2, the volume

Table 2. "Antisolvent Screening” to Determine Suitable Wash Solvent Mixture for Washing 1 to Prevent Nucleation of Particles from Mother Liquor and Reduce Paracetamol Dissolution $^{a}$

\begin{tabular}{|c|c|c|c|}
\hline & heptane & dodecane & isopropyl acetate \\
\hline ethanol & $50-50 \%(v / v)$ & $30-70 \%(\mathrm{v} / \mathrm{v})$ & $30-70 \%(v / v)$ \\
\hline isopropanol & $50-50 \%(v / v)$ & $60-40 \%(\mathrm{v} / \mathrm{v})$ & $10-90 \%(\mathrm{v} / \mathrm{v})$ \\
\hline isoamyl alcohol & $20-80 \%(\mathrm{v} / \mathrm{v})$ & $20-80 \%(\mathrm{v} / \mathrm{v})$ & $0-100 \%(\mathrm{v} / \mathrm{v})$ \\
\hline
\end{tabular}

${ }^{a}$ In bold is reported the percentage of pure crystallization solvent used to make the first wash solvent mixture.

ratio of crystallization and wash solvent that minimize API dissolution and avoid precipitation of fines and/or impurities during the first washing step is reported. These solvent mixtures used, as first wash solvent, were carefully selected to avoid paracetamol dissolution from occurring-as might occur if the first wash done using pure wash solvent, whilst also avoiding a drastic drop in solubility during washing to prevent API or impuritiy precipitation.

3.1.2. Effects on Filtration. Three different summary fittings were analyzed to determine parameters affecting the parameters related to cake filtration: cake volume, filtrate flow rate during filtration in port 1 , and cake resistance. Variation of cake volume (Figure 5) after filtration in port 1 was mainly affected by driving force, the nature of the crystallization solvent selected (cry). The coefficient plot (Figure 5) shows low reproducibility value caused by the variation of results obtained within the center points (replicates of each response is reported in the Supporting Information section). The $R^{2}$ and $Q^{2}$ values showed good fit between data and model and the model capability to predict responses. The variation of cake volume after filtration seems to be affected by the driving force (FP) applied during filtration that has a direct impact on the compressibility of the cake. As reported elsewhere, ${ }^{3}$ organic powder generally shows a compressibility index lower or in some cases higher than one. From experimental approach, the compressibility index of the different paracetamol grades was verified to be in this range (micronized compressibility index is equal to 0.2327 and for typical crystalline is 0.3976 ). Cake volume appeared to be affected by the nature of the crystallization solvent used, mainly ethanol and isoamyl alcohol, suggesting the impact of the solvent density. In the case of isoamyl alcohol, the final cake volume was higher with respect to the other crystallization solvents (ethanol, $0.789 \mathrm{~g} / \mathrm{mL}$, isopropanol, $0.786 \mathrm{~g} / \mathrm{mL}$ and isoamyl alcohol, 0.81 $\mathrm{g} / \mathrm{mL})$, showing how denser solvent can reduce the capability of cake packing.

The filtrate flow rate (Figure 6) was another key parameter used to evaluate the processability of the slurry. ${ }^{3}$ The filtrate flow rate seems to be affected by crystallization solvent properties, the driving force applied, and by the PSD (grade). The coefficient plot (Figure 6) shows low reproducibility value caused by the variation of results obtained within the center points (replicates of each response is reported in the Supporting Information section). The $R^{2}$ and $Q^{2}$ values showed modest fit between data and model and the model capability to predict responses. The characteristics of the crystallization solvent used affect the filtrate flow rate. This could be related with the viscosity of the mother liquor. As described from the Darcy's equation (volumetric flow rate), ${ }^{43}$ faster flow rates were observed for less viscous solvents (ethanol, $1.61 \mathrm{cP}$, isopropanol, $2.88 \mathrm{cP}$,

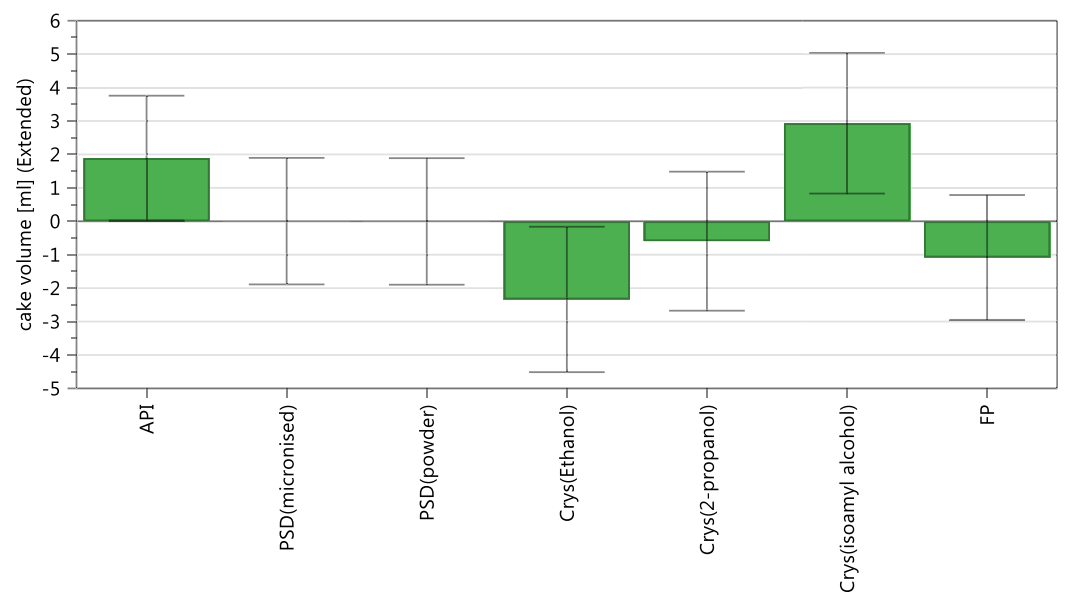

Figure 5. DoE variables that affect cake volume during filtration, $R^{2}=0.53, Q^{2}=0.26$, reproducibility $=-0.2$. 


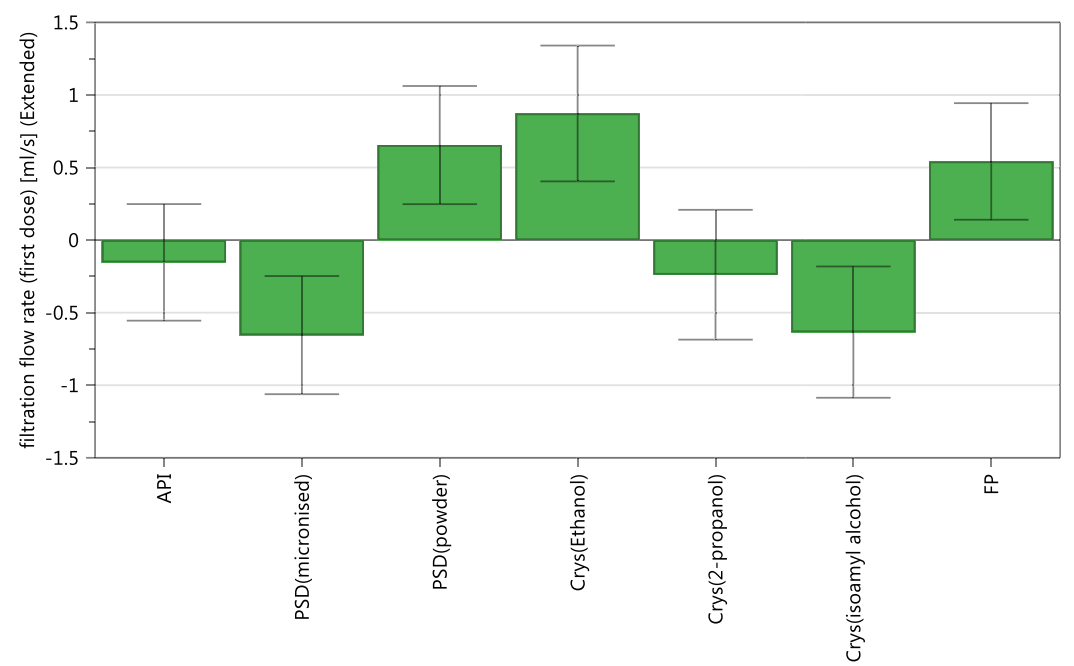

Figure 6. DoE variables that affect filtrate flow rate during filtration, $R^{2}=0.69, Q^{2}=0.44$, reproducibility $=1$.

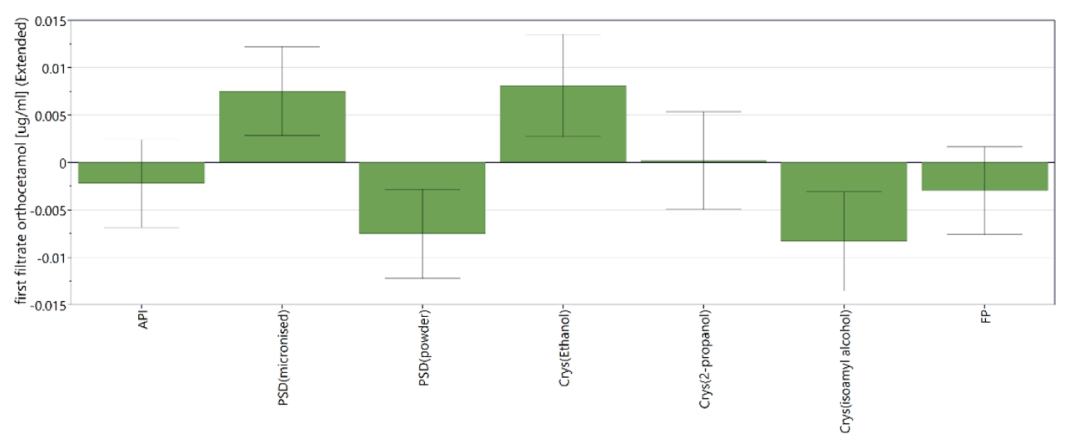

Figure 7. DoE variables that affect the concentration of orthocetamol in the first filtrate collected during filtration, $R^{2}=0.69, Q^{2}=0.44$, reproducibility $=1$.

isoamyl alcohol, $4.81 \mathrm{cP})$. As expected also the filtration driving force is positively affecting the filtrate flow rate: the higher the driving force, the higher the filtration flow rate achieved.

The grade of paracetamol from which the filter cake was formed seems affecting the filtrate flow rate: ${ }^{43}$ during filtration, finer particles tended to migrate towards the filter medium reducing the void volume and increasing the tortuosity of the cake adjacent to the filter medium. This phenomenon impacted also cake resistance, resulting in a gradient of alpha along the axis of the cake; ${ }^{44,45}$ this also slows washing and deliquoring, potentially causing higher moisture content in the deliquored cake. As known, cake resistance is calculated using the filtrate flow rate, as described by the Darcy's equation. ${ }^{43}$ Increasing the solid content in slurry and reducing driving force also reduced the filtrate flow rate. This is in agreement with the findings in Figure 6, as the impact of solid loading is negatively related to the filtrate flow rate.

Figure 7 shows that the selection of crystallization solvent also potentially impacted crystal purity, not only the filtration performances (Figures 5 and 6).

As seen from Figure 7, the concentration of orthocetamol removed during filtration is affected by the grade of the paracetamol used to generate the cake and by the nature of the crystallization solvent. The coefficient plot (Figure 7) shows good reproducibility value and good fit between data and model and the model capability to predict responses. The reason of this correlation between impurity removal and crystallization properties can be correlated to two different solvent properties:
- Solubility of the impurity in the crystallization solvent: the higher the impurity solubility, the bigger the quantity of impurity dissolved into the filtrate and the higher the removal during filtration; Figure 7 indeed shows a direct correlation between the concentration of orthocetamol removed and the solubility of this compound in the solvent. The solubility of orthocetamol in ethanol, 2propanol, and isoamyl alcohol was predicted using COSMOTherm method, and the solubility of orthocetamol was observed to be higher in ethanol (the solubility of orthocetamol in ethanol is $0.106 \mathrm{~g} / \mathrm{g}$ at $22{ }^{\circ} \mathrm{C}$, the solubility of orthocetamol in 2-propanol is $0.056 \mathrm{~g} / \mathrm{g}$ at 22 ${ }^{\circ} \mathrm{C}$, and the solubility of orthocetamol in isoamyl alcohol is $0.044 \mathrm{~g} / \mathrm{g}$ at $22{ }^{\circ} \mathrm{C}$ ). However, a disadvantage of choosing a solvent in which API related impurities are soluble is that the API is also likely to be quite soluble causing a corresponding reduction of crystallization yield. ${ }^{1}$ Of the three crystallization solvents evaluated in this study isoamyl alcohol appears to be the most promising candidate based on the quantity of API remaining in solution at $20{ }^{\circ} \mathrm{C}$ (ethanol, $0.184 \mathrm{~g} / \mathrm{g}$ of solvent, isopropanol, $0.109 \mathrm{~g} / \mathrm{g}$, isoamyl alcohol, $0.047 \mathrm{~g} /$ $\mathrm{g}$ at $20^{\circ} \mathrm{C}$ ). However, analyzing the impurity concentration in the mother liquors, the capability of this solvent to remove impurities is lower than the other two solvent due to lower API and impurity solubility and higher viscosity. Therefore, the second most promising crystal- 


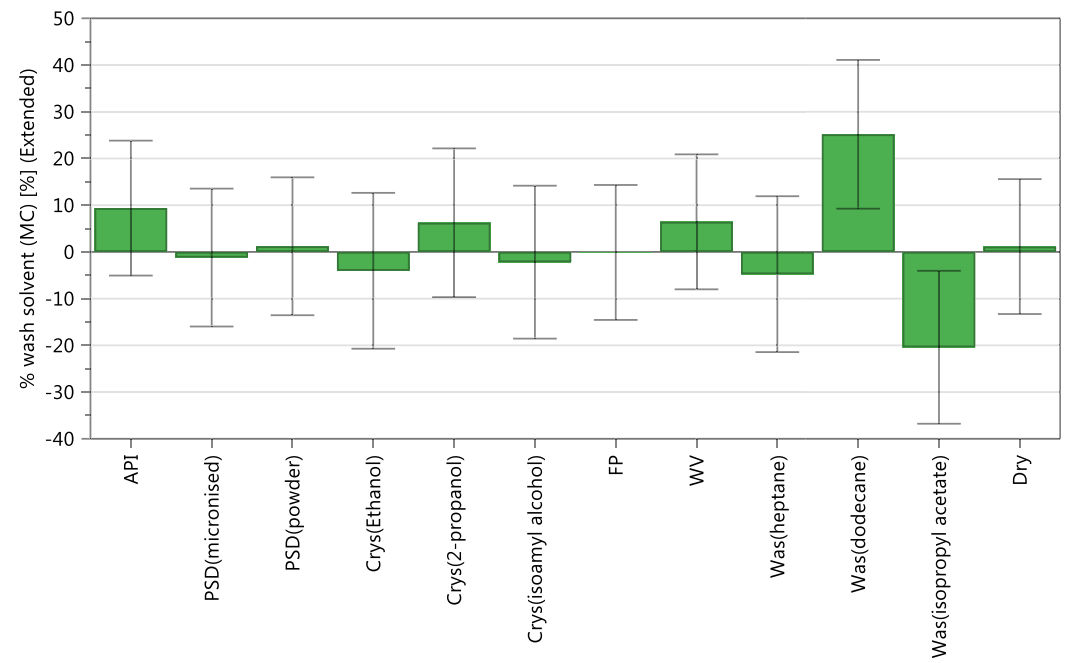

Figure 8. Fitting summary of variable affecting the relative percentage of wash solvent in the dried cake moisture content, $R^{2}=0.63, Q^{2}=-0.2$, reproducibility $=0.97$.

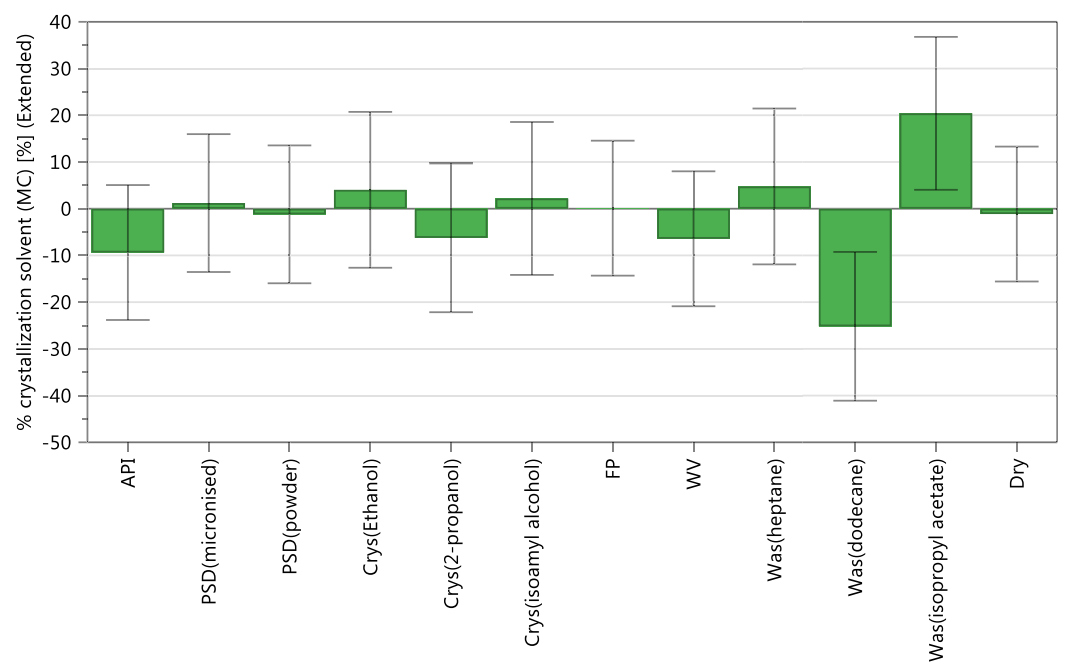

Figure 9. Fitting summary of variable affecting the relative percentage of crystallization solvent in the dried cake moisture content, $R^{2}=0.63, Q^{2}=-0.2$, reproducibility $=-0.2$.

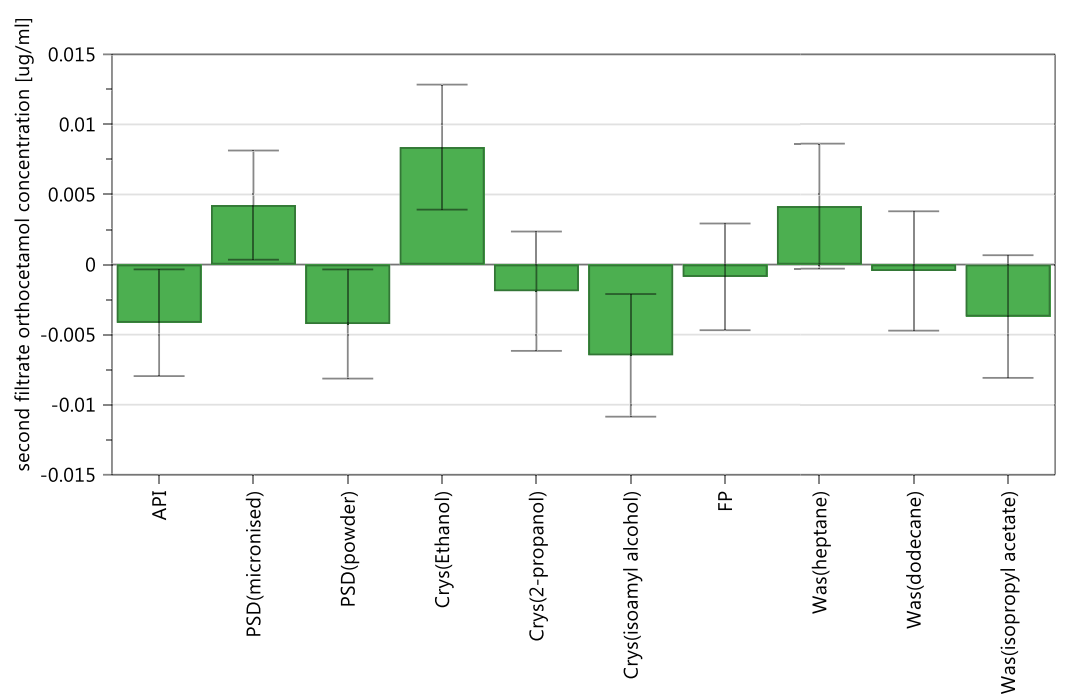

Figure 10. Second filtrate orthocetamol concentration fittings with DoE variables, $R^{2}=0.77, Q^{2}=0.51$, reproducibility $=0.64$. 


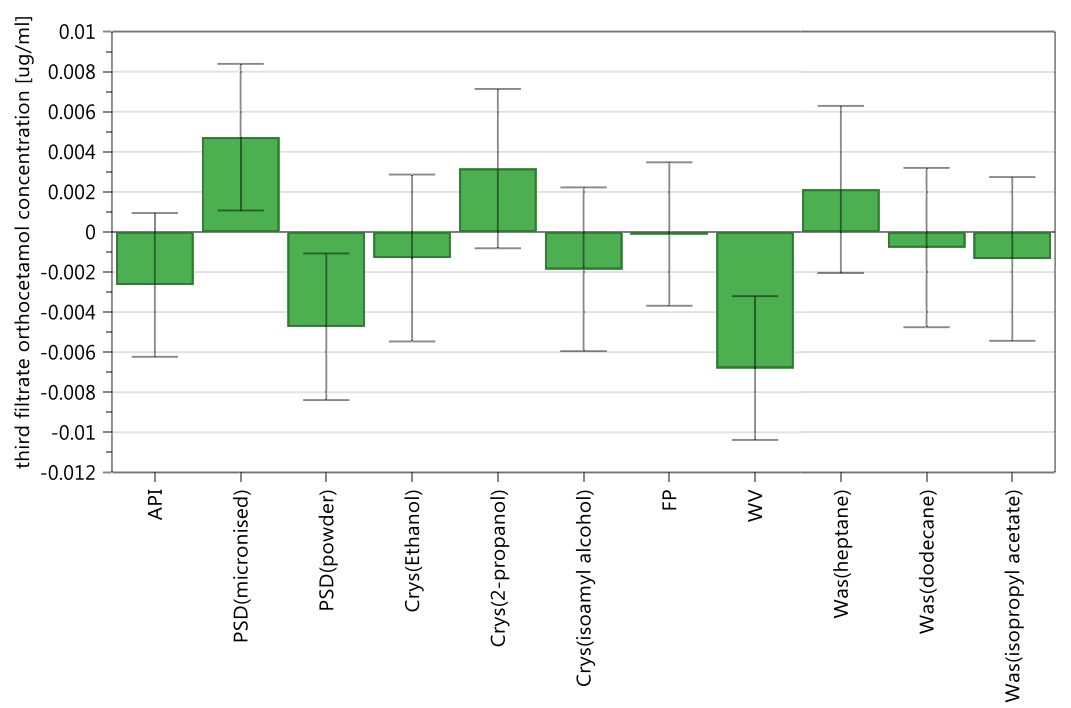

Figure 11. Dependence of the concentration of the impurity orthocetamol in the different wash solvents on the DoE variables, $R^{2}=0.69, Q^{2}=0.37$, reproducibility $=0.96$.

lization solvent is 2-propanol for its low API solubility and high impurity solubility.

- The viscosity of the solvent inversely affect the capability to remove the impurity, as seen in the case of isoamyl alcohol: higher the solvent viscosity, lower the quantity of impurity removal. This effect is here amplified by the low impurity solubility in isoamyl alcohol. The increased viscosity makes it more difficult to remove the solvent from small capillaries in the cake, reducing the efficiency in displacing mother liquor during washing. ${ }^{1}$ As suggested in previous research, the viscosity of mother liquor and wash solvent should be similar to promote good displacement washing. ${ }^{46}$

3.1.3. Effects on Washing. To investigate how the variables selected in the DoE affect washing, the effect of wash driving force, wash solvent properties, wash quantity, and the interaction between mother liquor and wash solvent were investigated with regard to the individual impurity concentrations in both filtrate and cake. The \% of wash solvent relative to the overall residual solvent quantity after drying, the ABI index and the extent of agglomeration were also investigated.

The residual moisture content composition, evaluated as relative percentage of residual mother liquor (Figure 9) and wash solvent (Figure 8) after drying, varies in relation to the properties of the wash solvent. The coefficient plot (Figures 8 and 9) shows good reproducibility value and good fit between data and model; however, the model capability to predict responses is not adequate to get good model prediction. The property that seems to affect the residual wash and mother liquor solvent content after drying is the boiling point of the wash solvent. $n$-Dodecane has a high boiling point and so becomes a dominant factor when employed as the wash solvent. In case the boiling point of the crystallization solvent is higher than the wash solvent, a relative abundance of residual crystallization solvent is expected (e.g., isopropyl acetate and $n$-heptane).

The effect of the selected DoE factors on the orthocetamol concentration in the second filtrate (wash 1) is shown in Figure 10. The paracetamol grade, solid content, and properties of the crystallization solvent mainly affect the removal of orthocetamol during the first wash. The coefficient plot (Figures 8 and 9) shows a good reproducibility value and good fit between data and model and the model capability to predict responses. API solid load and particle size grade also affected impurity removal: typical crystalline paracetamol has larger crystals which form larger interparticle channels where the solvent can easily flow and displace any mother liquor present. ${ }^{43}$ The cake height also affected the wash performance, which can be seen in Figure 10. Higher the cake, more the chance to trap impurity and so forming a gradient of purity, where the surface of the cake shows the purest part, while the cake near the filter and near the walls shows the highest impurity content.

During wash 1, as reported in Section 3.1.1, the wash solvent used was a mixture of pure crystallization and wash solvent. As seen in Figure 7, the solvent properties that mainly affect the impurity removal are the impurity solubility and the solvent viscosity. From Figure 10, the combination of ethanol as the crystallization solvent and $n$-heptane as wash solvent shows an enhancement the purity of cake, higher than other solvents combinations. Conversely the combination of isoamyl alcohol as the crystallization solvent and isopropyl acetate as the wash solvent yields the poorest washing outcome due to the big difference in the solvent viscosity and the 1 order of magnitude higher API solubility in isopropyl acetate $\left(0.0076 \mathrm{~g} / \mathrm{g}\right.$ at $\left.25{ }^{\circ} \mathrm{C}\right)$ with respect to the other wash solvents ( $n$-heptane, $0.0001 \mathrm{~g} / \mathrm{g}$ and $n$-dodecane $0.0007 \mathrm{~g} / \mathrm{g}$ at $25^{\circ} \mathrm{C}$ ).

Figure 11 shows how the selected factors affect the concentration of orthocetamol impurity in filtrate removed from the filter cake during wash 2. The coefficient plot (Figure 11) shows good reproducibility value and good fit between data and model, and model and the model capability to predict responses. This plot needs to be considered in the opposite way compared to Figure 10. Here, the presence of higher concentrations of the impurity in the third filtrate relates to poor washing. This is mainly influenced by the grade of paracetamol, the properties of the crystallization and wash solvents (solubility and viscosity), the driving force used, and the quantity of wash solvent used. The PSD of the cake can be correlated to the porosity and tortuosity of the cake. Higher cake tortuosity, as seen in micronized paracetamol, increases the propensity to trap impure mother liquor in the cake during 


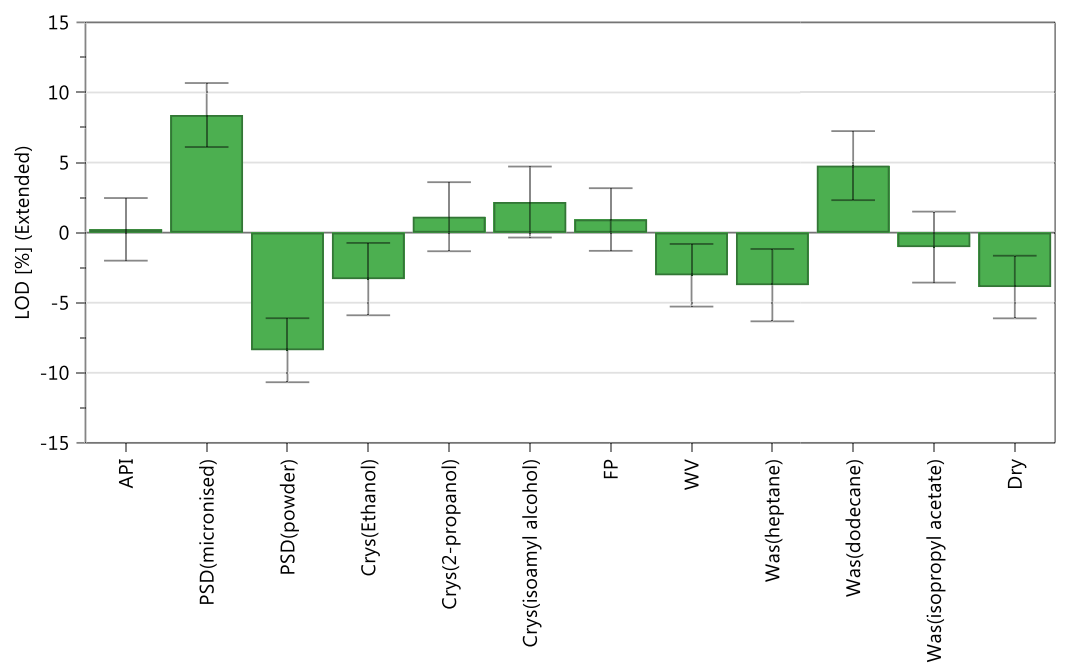

Figure 12. DoE variables that affect LOD of the dried samples, $R^{2}=0.92, Q^{2}=0.59$, reproducibility $=0.99$.

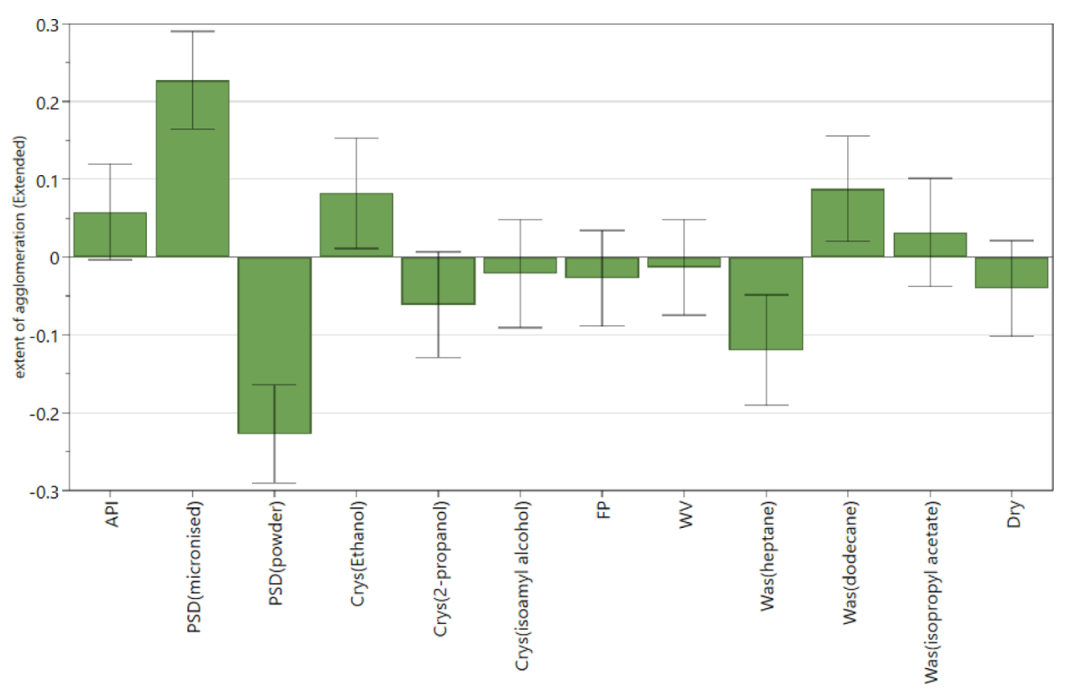

Figure 13. DoE variables that affect extent of agglomeration of the dried samples, $R^{2}=0.9, Q^{2}=0.55$, reproducibility $=0.9$.

filtration and wash 1 and lowers the capability of wash 2 to completely remove the impure mother liquor. ${ }^{43,47}$

The properties of crystallization and wash solvent affecting the washing efficiency in wash 2 are the solubility of the impurity and viscosity. The effect of $n$-dodecane should be similar to that of $n$-heptane, due to their similar viscosity ( $n$-heptane $0.4 \mathrm{cP}, n$ dodecane $1.36 \mathrm{cP}$, isopropyl acetate $0.8 \mathrm{cP}$ from Detherm database $\left.{ }^{48}\right)$. Further investigation into the effect of dodecane washing needs to be considered, even though fitting validity and reproducibility show high values. As reported in Section 3.1.2, Figure 7, isopropanol (2-propanol) or ethanol are considered the best cases of mother liquor because the API loss by dissolution in mother liquor is less than ethanol, due to the relative lower solubility. However, to remove the possible impurities deposited on the crystal surface, ethanol is suggested as the solvent, to allow partial crystal surface dissolution and therefore prevent impurity incorporation into the isolated material.

From Figure 11, it is possible to infer that the ideal isolation strategy was the washing of a small typical crystalline paracetamol cake with an ethanol- $n$-heptane mixture in wash 1 and with pure $n$-heptane in wash 2 using a total of four void volumes of wash solvent ( 1 in wash 1 and 3 in wash 2 ), using a low driving force to maximize the contact time to enhance dilution and diffusion washing mechanisms.

3.1.4. Effects on Drying. Drying was accomplished in port 5, without agitation, by flowing ambient air through the wet cake under reduced pressure. Lekhal et al. ${ }^{19}$ reported that wet particles tend to agglomerate during static drying under reduced pressure. The lack of agitation and consequent absence of disruption of aggregates allows strong interparticle bridges to form as solute saturated solvent evaporates from the points of contact between particles. The supply of material to form interparticle bridges was determined by the quantity of residual solvent evaporated and the amount of solute dissolved in it.

The effects of the variables investigated in the DoE; PSD, extent of agglomeration (particles bigger than $1 \mathrm{~mm}$ ), agglomerate strength of the final dried material, and the LOD after drying are summarized in the subsequent plots.

Figure 12 focuses on the final solvent content in dried samples (LOD). The coefficient plot (Figure 12) shows good reproducibility value and good fit between data and model and the model capability to predict responses. The factors which influenced this in order of decreasing importance are the paracetamol grade, wash solvent identity, volume of wash solvent used, nature of the crystallization solvent, paracetamol 


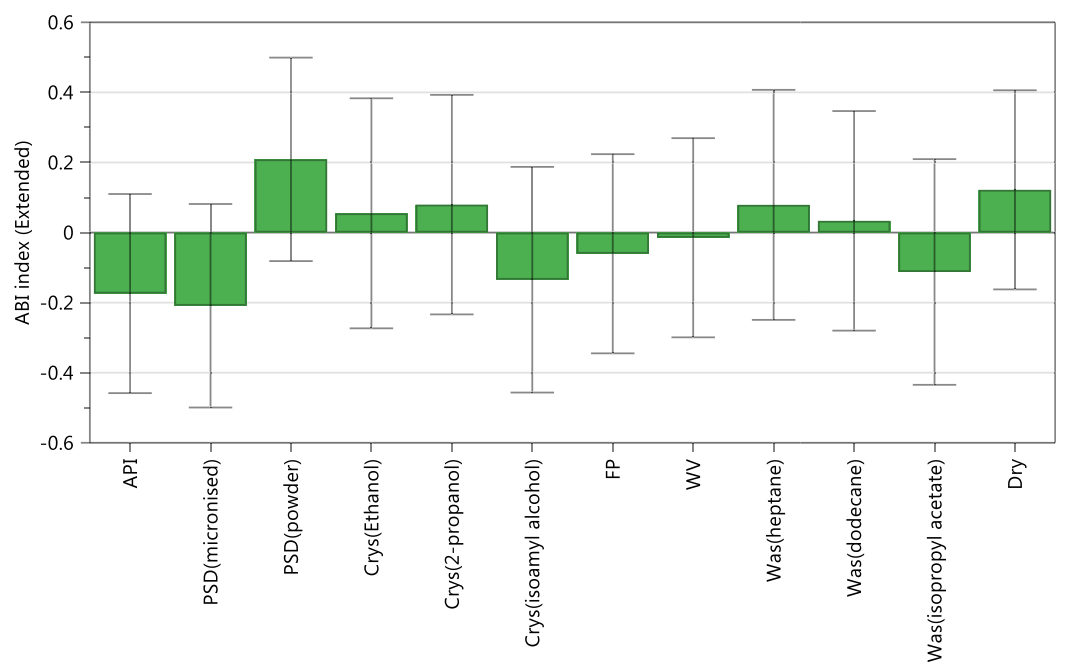

Figure 14. DoE variables that affect $\mathrm{ABI}$ index of the dried samples, $R^{2}=0.39, Q^{2}=-0.2$, reproducibility $=1$.

grade, and drying time. There is an inverse correlation between particle size and the LOD: the lower the particle size the higher the quantity of residual solvent retained. The wash solvent properties affecting the LOD are the wash solvent viscosity (more viscous solvents are more readily retained), the boiling point, and enthalpy of vaporization of the wash solvent that affect the ease of removal during drying, where $n$-heptane and isopropyl acetate are more easily removed than dodecane ( $n$ heptane $98.42^{\circ} \mathrm{C}, 36.6 \mathrm{~J} / \mathrm{mol}$, isopropyl acetate $89^{\circ} \mathrm{C}, 37 \mathrm{~J} / \mathrm{mol}$, dodecane $216.2{ }^{\circ} \mathrm{C}, 62.1 \mathrm{~J} / \mathrm{mol}$ ). The amount of wash solvent used to displace the mother liquor affects the LOD: in cases where the volatility of the wash solvent is higher than the mother liquor, increasing the volume of wash solvent promotes the removal of the mother liquor and therefore the reduction of the LOD. The crystallization solvent properties affecting the LOD are the solvent viscosity and volatility. Ethanol, the least viscous and most volatile crystallization solvent, is retained least, causing a reduction of the LOD. As expected, the drying time is affecting the LOD: longer drying produces a drier product.

Combining all these factors, the most favorable conditions occurred under the following conditions: API particle size was large, ethanol was the crystallization solvent, washing was completed with four cake void volumes of $n$-heptane using a low driving pressure to promote displacement, diffusional, and dilution washing, and this was followed by an extended drying period.

The coefficient plot (Figures 13 and 14) shows a good reproducibility value and good fit between data and model. Figure 13 shows good model capability to predict responses, while Figure 14 does not, showing that the effect plot does not show meaningful factor-responses correlations. It can be seen from Figure 13 that solid loading, paracetamol PSD, the nature of the crystallization and wash solvents, and the volume of wash solvent affected the extent of agglomeration. The mechanical strength of the agglomerates formed (hard or soft agglomerates, described by the $A B I$ index) seems to be affected by the paracetamol grade and solid load, by the nature of the crystallization and wash solvent, and by the drying time. The higher solid loading increased the agglomeration propensity whilst producing harder agglomerates. This effect is due to the mechanism of drying. ${ }^{20}$ During this constant rate drying step, ${ }^{49}$ the drying front progresses from the cake surface through to the bulk whilst the moisture content in the cake decreases linearly and it is only limited by the gas flow. During this step, agglomeration starts from the upper surface and slowly progresses through the bulk where the transport of unbonded moisture is occurring through the particle-particle capillaries. In case of thin cakes, if the material in the upper cake portion stays in contact with the solvent for longer periods, then the material after drying has a rather hard shell or crust and a relatively soft core. On the contrary, for thicker cakes, capillary forces cannot effectively transport the moisture from the bulk of the cake to the surface. In this case, after constant rate drying, the process is driven by moisture diffusion through the cake during the falling rate period (slower drying rate), causing an even distribution of cake moisture and formation of a single solid block.

The particle size and particle shape played a role on deliquoring results: as reported by Wakeman, ${ }^{43}$ increasing particle size shortens deliquoring time due to the increase in gas flow rate through the cake. On the contrary, fine solids provide larger surface area than bulky particles, producing faster drying. Effective moisture removal during the constant rate period was affected by surface area, while the internal particle morphology (or porosity) limits the falling rate period. Moreover, PSD affected the enthalpy transfer mechanism: as a particle dries, the outer layers shield further heat propagation and form a diffusion barrier. In the case of large bulky porous particles, removing all the liquid from the core requires prolonged drying times. Therefore, whilst finer particles dry rapidly, the larger particles begin to dominate the whole process. Wide PSDs increased the risk of agglomerate formation and cake hardening due to finer particles located in small voids of the cake that can act as bridge formation agents. ${ }^{50}$ On the other hand, finer particles tended to form hard agglomerates.

As reported in Figures 13 and 14, also the nature of crystallization and wash solvent also affect the agglomeration propensity and the strength of agglomerates during drying. One approach to reduce agglomeration is therefore to tailor the wash solvent composition to minimize concentration of the highly soluble component before the drying stage. Papageorgiou et al. ${ }^{51}$ investigated how solvent selection can influence particle agglomeration analyzing the effect of solvent selection and critical moisture content. ${ }^{52}$ From Figure 13, isoamyl alcohol could be considered a good candidate as crystallization solvent, but, as stated in Section 3.1.4, due to the different viscosity with 
respect to the wash solvent isoamyl alcohol was difficult to remove during washing. This may then cause bridge formation with high mechanical resistance (low ABI index), as seen in Figure 14, where the $A B I$ index seems to be influenced by the nature of the crystallization and wash solvents. Therefore, isopropanol or ethanol was preferred as crystallization solvent, even if ethanol showed higher propensity to form agglomerates.

The extent of agglomeration can be reduced by increasing the quantity of wash solvent: increasing the wash solvent volume of the pure wash solvent (wash 2) from 1 to 3 cake void volumes causes a drastic reduction of crystallization solvent/mother liquor trapped in the cake during the drying process. The best wash solvent to use for reducing agglomeration propensity is $n$ heptane due to the very low API solubility (see Supporting Information section) and the lower boiling point and enthalpy of vaporization. Even if $n$-dodecane showed solubility similar to $n$ heptane, this solvent has the highest boiling temperature; thus, during drying, the lower drying rate would also cause agglomeration. Isopropyl acetate was the poorest wash solvent, as its high API solubility allowed the formation of extensive agglomerates with a low ABI index (hard agglomerates). Finally, agglomeration and strength of aggregates can be reduced by increasing the drying time.

PSD of particles smaller than $1 \mathrm{~mm}$ were analyzed to determine if agglomeration mechanisms were also observed in single particles. In general, the particle size increase was observed in all of the samples. As seen for the extent of agglomeration, PSD of single particles was affected by the solvent selection, paracetamol grade, wash volume used, driving force (reducing the driving force increases in the wash solvent contact time and removal of impurities and mother liquor), and drying time. The PSD plots of the raw paracetamol compared with the different samples are reported in the Supporting Information.

3.2. Semicontinuous Run. To verify the transferability of the isolation strategy developed in optimization batch mode, a semicontinuous test was carried out using the CFD25 in production mode (details in the Materials and Methods section); optimized isolation parameters were qualitatively selected using the correlation plots. The set point validation tools provided by MODDE to identify the optimized parameter region could not be used due to the qualitative and quantitative nature of factors selected. In particular, in Sections 3.1.2, 3.1.3, and 3.1.4, detailed descriptions of the method used to select the optimal isolation parameter are reported. The parameters selected are reported in Table 3. The suspension was prepared using the same procedure described in the Materials and Methods section.

The semicontinuous run lasted for $10 \mathrm{~h}$ and $40 \mathrm{~min}$. After every 7 indexes (i.e., after every 7 cakes were filtered in port position 1), an automatic WIP sequence was carried out to avoid filter blinding and therefore increase the overall throughput during extended semicontinuous runs. The WIP sequence is described in Section 2.4.3.1. In total, $724 \mathrm{~g}$ of semidry material was produced with a throughput of $1.13 \mathrm{~g} / \mathrm{min}$ (approximately $68 \mathrm{~g} / \mathrm{h}$ ). The average LOD was $12.1 \pm 5.2 \%$ with a mean residual solvent composition of $83.7 \pm 0.2 \%$ of wash solvent and $16.3 \pm$ $0.2 \%$ of crystallization solvent was produced with a throughput of $1.13 \mathrm{~g} / \mathrm{min}$ (approximately $68 \mathrm{~g} / \mathrm{h}$ ). A sample was collected for every full rotation of the carousel. A total of eight samples were collected after drying and analyzed to determine the consistency of samples throughout the semicontinuous run and
Table 3. Isolation Strategy Selected for the Semicontinuous Run

\begin{tabular}{|c|c|}
\hline suspension properties & range \\
\hline mother liquor composition & $\begin{array}{l}\text { saturated solution of paracetamol in } \\
\text { ethanol, containing } 2 \% \\
\text { mol/mol of acetanilide, and } \\
\text { metacetamol }\end{array}$ \\
\hline solid load $(\%, w / w)$ & 25 \\
\hline slurry dose feed in port $1(\mathrm{~mL})$ & 65 \\
\hline $\begin{array}{l}\text { driving force filtration and washing } \\
\text { (mbar) }\end{array}$ & 500 \\
\hline wash solvent 1 & ethanol $/ n$-heptane $=50: 50(\% \mathrm{v} / \mathrm{v})$ \\
\hline wash solvent 2 & $n$-heptane \\
\hline $\begin{array}{l}\text { wash solvent } 1 \text { volume } \\
\text { (corresponding to cake void volumes) }\end{array}$ & 0.44 \\
\hline $\begin{array}{l}\text { wash solvent } 2 \text { volume } \\
\text { (corresponding to cake void volumes) }\end{array}$ & three washes of 0.44 void fractions \\
\hline drying time (s) & 180 \\
\hline drying gas temperature $\left({ }^{\circ} \mathrm{C}\right)$ & room temperature $\left(25^{\circ} \mathrm{C}\right)$ \\
\hline
\end{tabular}

to compare the properties of these samples with the properties predicted with the screening DoE.

The residual solvent content and composition obtained during the semicontinuous run and the data predicted by the DoE are quite different: the predicted LOD is close to zero, while the composition of the residual solvent is $50.4 \%$ as wash solvent and $49.6 \%$ of crystallization solvent. LOD and residual solvent composition of each sample analyzed is reported in the Supporting Information section. It is thought that this may be partially due to a lower drying gas flowrate through each cake when using production mode, compared to the flowrate through the cake in optimization mode. When drying in optimization mode, the gas flows through a $4 \mathrm{~mm}$ ID, $2 \mathrm{~m}$ length heated transfer line and one cake. When drying in production mode, the gas flows through the same heated transfer line and then shared between 5 cakes. The gas flowrate will be improved on future units by providing a larger ID heated transfer line. Pressure regulators on the inlet of the drying gas will be included to allow the use of compressed air with an inlet pressure of +250 mbar. In addition to these improvements, a floating base has been designed for the filter base, allowing for an improved seal between the base of the carousel and the filter base on future units.

The discrepancy of measured and expected values could also be caused by some issues observed during the semicontinuous run. A summary of the issues observed and the solutions to these challenges have been outlined in Section 3.2.1.

Filtration flow rate and cake resistance of the different samples collected during the semicontinuous run were calculated to determine the consistency of filtration (Table 4).

The flow rate gradually increases with the number of cycles, reaching a stable value after cycle 3: clean in place takes place every 7 cakes formed, this prevents blockage of the filter media with consequent increase of the filtrate flow rate. To get comparable flow rates with respect to the first run and those following, it is recommended that the unit is washed thoroughly at the end of each semicontinuous run to prevent crystallization of the material that blocks the system at the beginning of a future run.

Cake resistance values of the different cakes show comparable values, showing that the filtration process is consistent throughout the entire semicontinuous run (Table 4).

Comparing flow rate and cake resistance of the semicontinuous run with the values predicted with the DoE model, 
Table 4. Calculated Values of Flow Rate and Cake Resistance During Filtration in Port 1 of the Different Samples Collected During the Semicontinuous Run

\begin{tabular}{ccc} 
flow rate $(\mathrm{mL} / \mathrm{s})$-mean & $\begin{array}{c}\text { cake resistance }(\mathrm{m} / \mathrm{kg}) \text {-mean } \\
0.0253 \mathrm{~mL} / \mathrm{s}, \mathrm{st} \mathrm{dev} \\
0.0084 \mathrm{~mL} / \mathrm{s}\end{array}$ & $\begin{array}{c}10^{10} \mathrm{~m} / \mathrm{kg}, \mathrm{st} \mathrm{dev} \\
3.41 \times 10^{10} \mathrm{~m} / \mathrm{kg}\end{array}$ \\
sample & 0.0097 & $1.39 \times 10^{11}$ \\
1 & 0.0180 & $8.76 \times 10^{10}$ \\
2 & 0.0293 & $5.09 \times 10^{10}$ \\
3 & 0.0310 & $4.54 \times 10^{10}$ \\
4 & 0.0329 & $4.24 \times 10^{10}$ \\
5 & 0.0301 & $4.34 \times 10^{10}$ \\
6 & 0.0317 & $4.22 \times 10^{10}$ \\
7 & 0.0200 & $6.37 \times 10^{10}$ \\
8 & & \\
\hline
\end{tabular}

the values are orders of magnitude of difference (batch predicted values: flow rate $=2.2-2.4 \mathrm{~mL} / \mathrm{s}$ and cake resistance $\approx 10^{9} \mathrm{~m} /$ $\mathrm{kg}$; semicontinuous run average values: flow rate $=0.025 \pm$ $0.008 \mathrm{~mL} / \mathrm{s}$ and cake resistance $=6.44 \times 10^{10} \pm 3.41 \times 10^{10} \mathrm{~m} /$ $\mathrm{kg}$ ). These discrepancies are mainly due to the extent of filter media obstruction: during the batch experiments, all of the ports are carefully cleaned before each run (approximately $1 \mathrm{~L}$ of WIP solvent was used to clean the entire carousel and filter plate after processing each cake in optimization mode), whereas during semicontinuous experiments after every 7 cakes formed, the automated WIP sequence draws a $25-30 \mathrm{~mL}$ aliquot of WIP solvent through ports 1 to 4 to wash the filter plates. Improving the WIP procedure used during semicontinuous operation can reduce the risk of filter media blockage and consequently improve the filtration flow rate and cake resistance.

Analyzing the cake purity of the eight samples, those were mainly formed of paracetamol with traces of acetanilide (area ratio paracetamol/acetanilide $=1: 0.013 \pm 0.0012$ ) with an average cake composition determined by HPLC of $133.44 \pm$ $22.25 \mu \mathrm{g} / \mathrm{mL}$ of paracetamol and $1.79 \pm 0.22 \mu \mathrm{g} / \mathrm{mL}$ of acetanilide. HPLC calibration curves and purity of each sample are reported in the Supporting Information section.

The isolated cakes were analyzed to obtain information about the extent of agglomeration, the particle-particle aggregation (aggregates size less than $1 \mathrm{~mm}$ ) and the agglomerate strength. Measured values of these product properties for each sample are reported in the Supporting Information section.

The samples collected during the semicontinuous run showed comparable extent of agglomeration: the mean value measured was $56.4 \pm 0.14 \%$. The strength of these agglomerates was consistent throughout the eight samples, showing the formation of hard agglomerates (mean ABI index was $0.28 \pm 0.15$ ). These values were compared with the values predicted by the DoE, and the results modeled are in good agreement with the experimental data (modeled extent of agglomeration corresponded to a range between 56 and $58 \%$, whereas the $\mathrm{ABI}$ index modeled was in a range of $0.3-0.35$ ). The formation of hard agglomerates is due to the presence of residual mother liquor in the dried cake which is able to promote strong particle-particle bridges formation.

Particle-particle aggregation was observed in all of the eight samples; mean volumetric diameter $\left(x_{50}\right)$ and sauter mean diameter (SMD) of the samples collected during the semicontinuous run corresponded to $85 \pm 7$ and $69 \pm 6 \mu \mathrm{m}$, whereas raw powder paracetamol presented $x_{50}$ and SMD values of 67 and $47 \mu \mathrm{m}$. Cumulative distribution graph of the samples is reported in the Supporting Information section.
3.2.1. Solutions for Resolving Issues Observed during Semicontinuous Run. Table 5 summarizes the issues observed during the semicontinuous run. Some of these issues have been resolved on the future units, and others are being addressed. The solutions to the challenges are also described in Table 5, all of which serve to reduce the risk of inconsistency of solvent removal during the filtration, washing, and deliquoring processes.

\section{CONCLUSIONS}

The pharmaceutical industry is in the process of embracing continuous manufacturing of APIs in order to reduce production cost, improve manufacturing flexibility, reduce infrastructure cost to improve consistency of API quality critical attributes, and to reduce manufacturing lead time and to improve sustainability by reducing waste generation.

To reduce time and to minimize material consumption during new drug/process development, it is fundamental that the isolation development strategy is studied using adaptable laboratory equipment to avoid extra investigation to adapt the design strategy to a semicontinuous isolation system.

The CFD25 can be used to first develop the isolation strategy in batch approach and then to isolate in semicontinuous mode slurries without the requirement of modifying the process design.

To verify the process transferability between batch and semicontinuous CFD25 production modes, a screening DoE approach was used to study the effect of API solid load, input PSD particles, crystallization solvent nature, isolation driving force, wash solvent nature, wash solvent volume used, and drying time to develop the isolation strategy to use during the run. The aim of the project was to verify the consistency of isolated material properties during the semicontinuous run and to get comparable material attributes between batch and semicontinuous production.

Material attributes considered were product purity, residual solvent content and composition, filtration properties (cake resistance and flow rate), agglomeration extent, and strength and particle-particle aggregate size. The unit's productivity and throughput were measured during the semicontinuous run.

By using the CFD25 in optimization mode, it was possible in 2 weeks to run a full set of DOE experiments and full product characterization to determine the best isolation strategy for the API analyzed. The duration of the work on the CFD25 was around 5 days.

The DoE predicted that the best isolation strategy would achieve an LOD close to zero, while the composition of the residual solvent would be 50.4 and $49.6 \%$ for wash solvent and crystallization solvent, respectively.

The isolation strategy selected during the screening DoE was replicated during $11 \mathrm{~h}$ of semicontinuous operation, where a total of eight samples were periodically collected to investigate process consistency, the sampling rate was every 7 th cake ejected.

Overall, $724 \mathrm{~g}$ of partially dried material with an average LOD of $12.1 \%$ was produced with a throughput of $1.13 \mathrm{~g} / \mathrm{min}$ (approximately $68 \mathrm{~g} / \mathrm{h}$ ). The total cycle time for filtration, washing, and drying for each cake was between 40 and $60 \mathrm{~min}$. The average residual solvent composition of the cakes was $84 \%$ of the wash solvent and $16 \%$ of the crystallization solvent.

The discrepancy in LOD and solvent composition values from the semicontinuous run compared to the predicted values from the DoE was due to a combination of reasons, including filter 
media blockage, solvent splashing causing incorrect detection of liquid level, and low drying gas flow through each cake. The solutions to these observations have been discussed in this paper and have been implemented in future designs, improving both robustness and performance of the AWL continuous filter dryer.

The flow rate during filtration, cake resistance, cake purity, extent of agglomeration, agglomerate strength, and aggregate size were consistent throughout the samples collected, showing that the unit can produce consistent isolated material. Comparing the measured product properties of the isolated material produced during the semicontinuous run and the corresponding data modeled from a DoE reveals that agglomerates and aggregates properties were comparable showing the capability of the unit to easily transfer a batch process development set of experiment to a semicontinuous process.

\section{ASSOCIATED CONTENT}

Supporting Information

The Supporting Information is available free of charge at https://pubs.acs.org/doi/10.1021/acs.oprd.9b00512.

Table S1: Material characteristics of the paracetamol grades; Figure S1: Cumulative distribution and distribution density of raw micronized paracetamol; Figure S2: Cumulative distribution and distribution density of raw powder paracetamol; Table S2: Main properties of the solvent used during this work; ${ }^{53-58}$ Table S3: Paracetamol solubility in the three different crystallization solvent used for this work; Table S4: Paracetamol solubility in the different wash solvent used for this work; Figure S3: Isopropanol-paracetamol saturated solution viscosity at different temperatures; ${ }^{56}$ Figure S4: Ethanol-paracetamol saturated solution viscosity at different temperatures; ${ }^{57}$ Figure S5: Isoamyl alcoholparacetamol saturated solution viscosity at different temperatures; ${ }^{58}$ Figure S6: Factors of the DOE; Figure S7: Responses of the DoE; Figure S8: Replicate plot showing the variability of cake volume through all the experiments; Figure S9: Replicate plot showing the variability of first filtrate flow rate through all the experiments. In blue are reported the three centre points; Figure S10: Replicate plot showing the variability of the residual wash solvent through all the experiments. In blue are reported the three centre points; Figure 11: Replicate plot showing the variability of the residual crystallisation solvent \% through all the experiments. In blue are reported the three centre points; Figure 12: Replicate plot showing the variability of the concentration of orthocetamol in the first filtrate through all the experiments. In blue are reported the three centre points; Figure 13: Replicate plot showing the variability of the concentration of orthocetamol in the second filtrate through all the experiments. In blue are reported the three centre points; Figure 14: Replicate plot showing the variability of the concentration of orthocetamol in the third filtrate through all the experiments. In blue are reported the three centre points; Figure 15: Replicate plot showing the variability of the LOD through all the experiments. In blue are reported the three centre points; Figure 16: Replicate plot showing the variability of the extent of agglomeration through all the experiments. In blue are reported the three centre points; Figure 17: Replicate plot showing the variability of 
the $A B I$ index through all the experiments. In blue are reported the three centre points; Figure S18: HPLC calibration curve of paracetamol; Figure S19: HPLC calibration curve of metacetamol and acetanilide; Table S5: LOD and composition of the residual solvent content after $180 \mathrm{~s}$ of drying of the samples produced during the semicontinuous run experiment; Figure S20: 4D contour plots of the variation of flow rate and cake resistance respect API solid load ( $w / w \%, y$-axis) and the isolation pressure (mbar, $x$-axis) predicted with the DoE model for cakes made with powder paracetamol in ethanol (crystallization solvent), washed three times with $n$ heptane, and dried with room temperature flowing air for $180 \mathrm{~s}$; Figure S21-Figure S41: HPLC peak area ratio of the different compounds present in filtrates collected during the isolation of sample exp1, exp2, exp3, exp4, exp5, exp6, exp7, exp8, exp9, exp10, exp11, exp12, exp13, exp14, exp15, exp16, exp17, exp18, exp19, exp20, and exp21; Figure S42: Images of the isolated cakes; Table S6: Paracetamol-acetanilide peak area ratio, concentration of paracetamol, acetanilide, and metacetamol $(\mu \mathrm{g} / \mathrm{mL})$ in the isolated cake produced during the semicontinuous run; Table S7: Extent of agglomeration (\%) and ABI index of the cake isolated and sampled during the semicontinuous run experiment; Figure S43: 4D Contour plots of the variation of extent of agglomeration and ABI index respect API solid load (w/w \%, $y$-axis) and the isolation pressure (mbar, $x$-axis) predicted with the $\mathrm{DoE}$ model for cakes made with powder paracetamol in ethanol (crystallization solvent), washed three times with $n$-heptane, and dried with room temperature flowing air for $180 \mathrm{~s}$; and Figure S44: Cumulative size distribution of the particles with size below $1 \mathrm{~mm}$ isolated during the semicontinuous run experiment. Comparison of size distribution of the samples collected with the initial raw material (dark gray). (PDF)

\section{AUTHOR INFORMATION}

\section{Corresponding Author}

Sara Ottoboni - EPSRC Centre for Innovative Manufacturing in Continuous Manufacturing and Crystallisation, University of

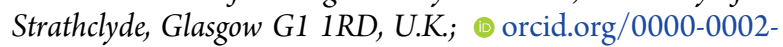
2792-3011; Email: sara.ottoboni@strath.ac.uk

\section{Authors}

Muhid Shahid - EPSRC Centre for Innovative Manufacturing in Continuous Manufacturing and Crystallisation, University of Strathclyde, Glasgow G1 1RD, U.K.

Christopher Steven - EPSRC Centre for Innovative Manufacturing in Continuous Manufacturing and Crystallisation, University of Strathclyde, Glasgow G1 1RD, U.K.; Alconbury Weston, Stoke-on-Trent ST4 3PE, U.K.

Simon Coleman - EPSRC Centre for Innovative Manufacturing in Continuous Manufacturing and Crystallisation, University of Strathclyde, Glasgow G1 1RD, U.K.; Alconbury Weston, Stokeon-Trent ST4 3PE, U.K.

Elisabeth Meehan - Pharmaceutical Technology and Development, AstraZeneca, Macclesfield SK10 2NA, U.K.

Alastair Barton - Alconbury Weston, Stoke-on-Trent ST4 3PE, U.K.

Paul Firth - Alconbury Weston, Stoke-on-Trent ST4 3PE, U.K.

Richard Sutherland - Alconbury Weston, Stoke-on-Trent ST4 3PE, U.K.
Chris J. Price - EPSRC Centre for Innovative Manufacturing in Continuous Manufacturing and Crystallisation and Department of Chemical and Process Engineering, University of Strathclyde, Glasgow G1 1RD, U.K.

Complete contact information is available at:

https://pubs.acs.org/10.1021/acs.oprd.9b00512

\section{Author Contributions}

All contributed with specific focus as indicated; S.O., M.S., and C.J.P. for the experimental part. A.B., P.F., S.C., R.S., and C.S. for the equipment design, fabrication and software development. E.M. for the REMEDIES project direction and managment.

\section{Notes}

The authors declare no competing financial interest.

\section{ACKNOWLEDGMENTS}

The authors wish to acknowledge the contributions of colleagues in each of their organizations. We are grateful to: Claire Macleod of AstraZeneca for industrial practice information. The authors wish to acknowledge our funders: C.J.P.: EPSRC Manufacturing Fellowship and the Centre for Innovative Manufacturing in Continuous Manufacturing and Crystallisation (grant ref. EP/L014971/1). S.O.: EPSRC Doctoral Training Centre for Innovative Manufacturing in Continuous Manufacturing and Crystallisation (grant ref. EPK503289). S.C.: Knowledge Transfer Partnership, Innovate UK (KTP no. 01280). C.S.: Knowledge Transfer Partnership, Innovate UK (KTP no. 010280). M.S.: Future Continuous Manufacturing and Advanced Crystallisation Research Hub (grant ref. EP/P006965/1). Alconbury Weston Ltd: REMEDIES (RE-configuring MEDIcines End-to-end Supply) project is part of the Advanced Manufacturing Supply Chain Initiative.

\section{ABBREVIATIONS}

AWL CFD20, continuous filter dryer prototype unit, version 1; AWL, Alconbury Weston Ltd; REMEDIES, reconfiguring medicines end-to-end supply; AWL CFD25, continuous filter dryer prototype unit, version 2; API, active pharmaceutical ingredient; FDA, Food and Drug Administration; PSD, particle size distribution; HPLC, high-performance liquid chromatography; $\mathrm{ABI}$ index, agglomerate brittleness index; ${ }^{1} \mathrm{H}$ NMR, proton nuclear magnetic resonance; HMI, human machine interface; DMSO- $d$, dimethyl sulfoxide- $d$; DoE, design of experiment

\section{ADDITIONAL NOTES}

${ }^{a}$ The significance of the two filtration stopping conditions; dryland or breakthrough; arise from the tendency for cracks to form in filter cakes as a result of deliquoring. Halting the filtration at dry land ensures that the cake is fully saturated and makes cracking unlikely but retains impure mother liquor in all the inter-particulate pores. Alternatively breakthrough occurs when the cake is deliquored sufficiently for air or nitrogen from above the cake to form bubbles on the low pressure side of the medium supporting the cake. In this case, more of the impure mother liquor is removed but the cake is very likely to have cracks running all the way through the cake from top to bottom making subsequent washing much less effective.

${ }^{b}$ Dead end filtration is the most common method of filtration. The slurry, with known composition, is placed in a pressurized chamber; a pressure drop is applied across the filter medium and the suspension is forced to move toward the medium, which 
allows the flow of the liquid but retains the solids. Consequently, a cake of solid particles is formed on the top of the medium as the filtrate passes through and its thickness increases with time. During this process, the cake continuously changes its structure due to compressive stress and these changes are estimated as change in local solidosity and local permeability; these changes in cake compaction affect the flow of the liquid through the cake and therefore the cake growth rates.

\section{REFERENCES}

(1) Ruslim, F.; Hoffner, B.; Nirschl, H.; Stahl, W. Evaluation of pathways for washing soluble solids. Chem. Eng. Res. Des. 2009, 87, $1075-1084$

(2) Kuo, M. T.; Barrett, E. C. Continuous filter cake washing performance. AIChE J. 1970, 16, 633-638.

(3) Ripperger, S.; Gösele, W.; Alt, C.; Loewe, T. Filtration, 1. Fundamentals. Ullmann's Encyclopedia of Industrial Chemistry; Major Reference Works, 2013.

(4) Beckmann, W. Crystallization Basic Concepts and Industrial Applications; WILEY-VCH Verlag GmbH \& Co. KGaA, 2013.

(5) Wakeman, R.; Tarleton, S. Solid Liquid Separation: Principles of Industrial Filtration, 1st ed.; Elsevier Science: Amsterdam, Netherlands, 2005.

(6) Business Insights: Global. http://bi.galegroup.com/global/ a rticle/G A L E \% 7 C A 290735580 /

049a9a3f271d08a0b7cf1523fb30cb02?u=ustrath, [cited March 17, 2018].

(7) Birch, M.; Marziano, I. Understanding and Avoidance of Agglomeration During Drying Processes: A Case Study. Org. Process Res. Dev. 2013, 17, 1359-1366.

(8) Perlmutter, B. A.; et al. A Treatise of Filter Cake Washing Mechanisms in Pressure and Vacuum Filtration Systems; BHS Filtration, [cited Nov 18, 2016].

(9) https://bhs-filtration.com/wp-content/documents/A Treatise of Filter Cake Washing Mechanisms.pdf.

(10) Tamrakar, A.; Gunadi, A.; Piccione, P. M.; Ramachandran, R. Dynamic agglomeration profiling during the drying phase in an agitated filter dryer: Parametric investigation and regime map studies. Powder Technol. 2016, 303, 109-123.

(11) Tien, C. Cake filtration research-a personal view. Powder Technol. 2002, 127, 1.

(12) Tien, C.; Bai, R.; Ramarao, B. V. Analysis of cake growth in cake filtration: Effect of fine particle retention. AIChE J. 1997, 43, 33-44.

(13) Tien, C.; Bai, R. An assessment of the conventional cake filtration theory. Chem. Eng. Sci. 2003, 58, 1323-1336.

(14) Bürger, R.; Concha, F.; H Karlsen, K. Phenomenological model of filtration processes: 1. Cake formation and expression. Chem. Eng. Sci. 2001, 56, 4537-4553.

(15) Stamatakis, K.; Tien, C. Cake formation and growth in cake filtration. Chem. Eng. Sci. 1991, 46, 1917-1933.

(16) Tiller, F. M.; Haynes, S.; Lu, W.-M. The role of porosity in filtration VII effect of side-wall friction in compression-permeability cells. AIChE J. 1972, 18, 13-20.

(17) Wakeman, R. J.; Tarleton, E. S. Filtration: Equipment Selection, Modelling and Process Simulation, 1st ed.; Elsevier Science Ltd.: Oxford, United Kingdom, 1999.

(18) Macleod, C. S.; Muller, F. L. On the Fracture of Pharmaceutical Needle-Shaped Crystals during Pressure Filtration: Case Studies and Mechanistic Understanding. Org. Process Res. Dev. 2012, 16, 425-434.

(19) Lekhal, A.; Girard, K. P.; Brown, M. A.; Kiang, S.; Glasser, B. J.; Khinast, J. G. The effect of agitated drying on the morphology of 1threonine (needle-like) crystals. Powder Technol. 2004, 270, 263-277.

(20) Kom, K.. P.; Cook, W.; Kougoulos, E. Impact of Laboratory Vacuum Contact Drying on Material Drying Rates and Physical Properties. Org. Process Res. Dev. 2011, 15, 360-366.

(21) Wong, K. W. S. Design of a Small-Scale Continuous Linear Motion Pharmaceutical Filtration Module, https://dspace.mit.edu/ handle/1721.1/60210\#files-area, [cited Sept 30, 2017].
(22) McWilliams, J. C.; Allian, A. D.; Opalka, S. M.; May, S. A.; Journet, M.; Braden, T. M. The Evolving State of Continuous Processing in Pharmaceutical API Manufacturing: A Survey of Pharmaceutical Companies and Contract Manufacturing Organizations. Org. Process Res. Dev. 2018, 22, 1143.

(23) Mollan, J. M. J.; Mayur, L. Continuous processing in pharmaceutical manufacturing. Pharmaceut. Manuf. Mag. 2004, 1-9.

(24) Kossik, J. Think Small: Pharmaceutical Facility Could Boost Capacity and Slash Costs by Trading in Certain Batch Operations for Continuous Versions, http://www.pharmamanufacturing.com, [cited Aug 20, 2018].

(25) US Food and Drug Administration, Centre for Drug Evaluation and Research: Guidance for Industry PAT A Framework for Innovative Pharmaceutical Manufacturing and Quality Assurance, http://www. fda.gov/cder/guidance/5815dft.htm, [cited Sept 20, 2018].

(26) Kossik, J. Operation of a Disposable Rotary Drum Filter; American Institute of Chemical Engineers, 2001; pp 4-9.

(27) Söhnel, O. Analysis of the precipitation reactor-separation equipment system. Continuous reactor and the rotary vacuum filter operating at the selected negative pressure drop. Collect. Czech. Chem. Commun. 1981, 46, 2364-2370.

(28) Kosonen, V. J. Continuous Drum Filter with Improved Agitator Structure. U.S. Patent 4,105,563A, 1978.

(29) Hillier, G. O. Continuous Rotary Disk and Drum Filter. U.S. Patent 2,092,252A, 1937.

(30) REMEDIES (RE-configuring MEDIcines End-to-end Supply) Advanced Manufacturing Supply Chain Initiative. Workstream App. "B"-Primary to Secondary, http://remediesproject.com/research-2/ project-structure/app-b/, [cited Sept 2, 2016].

(31) Murugesan, S.; Sharma, P. K.; Tabora, J. E. Design of Filtration and Drying Operations p315-346. Chemical Engineering in the Pharmaceutical Industry: R\&D to Manufacturing; Wiley: New York, 2010.

(32) Ruslim, F.; Hoffner, B.; Nirschl, H.; Stahl, W. Evaluation of pathways for washing soluble solids. Chem. Eng. Res. Des. 2009, 87, $1075-1084$

(33) Kossik, J. Small Scale Continuous Cake Filtration using the Disposable Rotary Drum Filter. Filtr. Sep. 2003, 40, 26-27.

(34) Hendriksen, B. A.; Grant, D. J. W. The effect of structurally related substances on the nucleation kinetics of paracetamol (acetaminophen). J. Cryst. Growth 1995, 156, 252.

(35) Kuvadia, Z. B.; Doherty, M. F. Effect of Structurally Similar Additives on Crystal Habit of Organic Molecular Crystals at Low Supersaturation. Cryst. Growth Des. 2013, 13, 1412.

(36) International Conference of Harmonisation of technical requirements for registration of pharmaceuticals for human use. ICH Harmonised Tripartite Guideline, 1999. Specifications: Test procedures and Acceptance Criteria for New Drug Substances and New Drug Products: Chemical Substances (Q6A).

(37) VDI-Handbuch Verfahrenstechnik und Chemieingenieeurwesen, Band 5: Spezielle Verfahrenstechniken, 2006. Mechanical solidliquid-separation by cake filtration. Overview. VDI 2762.

(38) Ellis, F. Paracetamol: A Curriculum Resource; Royal Society of Chemistry, 2002.

(39) Hendriksen, B. A.; Grant, D. J. W.; Meenan, P.; Green, D. A. Crystallisation of paracetamol (acetaminophen) in the presence of structurally related substances. J. Cryst. Growth 1998, 183, 629.

(40) Granberg, R. A.; Rasmuson, Å. C. Solubility of Paracetamol in Pure Solvents. J. Chem. Eng. Data 1999, 44, 1391-1395.

(41) Ottoboni, S.; Price, C.; Steven, C.; Meehan, E.; Barton, A.; Firth, P.; Mitchell, P.; Tahir, F. Development of a novel continuous filtration unit for pharmaceutical process development and manufacturing. $J$. Pharm. Sci. 2018, 108, 372.

(42) Zimmerman, J., Hilger, R., 2018. Devices for heating smalldiameter tubing and methods of making and using. Espacenet patent search website https://worldwide.espacenet.com/publicationDetails/ biblio $? \mathrm{FT}=\mathrm{D} \&$ date $=20180802 \& \mathrm{DB}=\mathrm{EPODOC} \&$ locale $=$ en $\mathrm{EP} \& \mathrm{CC}=\mathrm{WO} \& \mathrm{NR}=2018140344 \mathrm{~A} 1 \& \mathrm{KC}=\mathrm{A} 1 \& \mathrm{ND}=6 \#$, [cited April 30, 2019]. 
(43) Wakeman, R. The influence of particle properties on filtration. Sep. Purif. Technol. 2007, 58, 234.

(44) Willis, M. S.; Tosun, I. A rigorous cake filtration theory. Chem. Eng. Sci. 1980, 35, 2427-2438.

(45) Fathi-Najafi, M.; Theliander, H. Determination of local filtration properties at constant pressure. Sep. Technol. 1995, 5, 165-178.

(46) Dullien, F. A. L. Porous Media Fluid Transport and Pore Structure, 2nd ed.; Academic Press Inc., 1992.

(47) Ruslim, F.; Nirschl, H.; Stahl, W.; Carvin, P. Optimization of the wash liquor flow rate to improve washing of pre-deliquored filter cakes. Chem. Eng. Sci. 2007, 62, 3951-3961.

(48) Dechema. http://dechema.de/en/detherm.html, [cited Nov 18, 2016].

(49) Conder, E. W.; Cosbie, A. S.; Gaertner, J.; Hicks, W.; Huggins, S.; MacLeod, C. S.; Remy, B.; Yang, B.-S.; Engstrom, J. D.; Lamberto, D. J.; Papageorgiou, C. D. The Pharmaceutical Drying Unit Operation: And Industry Perspective on Advancing the Science and Development Approach for Scale-Up and Technology Transfer. Org. Process Res. Dev. 2017, 21, 420-429.

(50) Am Ende, D.; Birch, M.; Brenek, S. J.; Maloney, M. T. Development and Application of Laboratory Tools To Predict Particle Properties upon Scale-Up in Agitated Filter-Dryers. Org. Process Res. Dev. 2013, 17, 1345-1358.

(51) Papageorgiou, C. D.; Langston, M.; Hicks, F.; AM Ende, D.; Martin, E.; Rothstein, S.; Salan, J.; Muir, R. Development of Screening Methodology for the Assessment of the Agglomeration Potential of APIs. Org. Process Res. Dev. 2016, 20, 1500-1508.

(52) Lim, H. L.; Hapgood, K. P.; Haig, B. Understanding and preventing agglomeration in a filter drying process. Powder Technol. 2016, 300, 146-156.

(53) Celsius-process. http://www.celsius-process.com/pdf/ isopropanol.pdf, [cited Aug 20, 2018].

(54) DDBST GmbH. http://www.ddbst.com/en/EED/PCP/VIS C11.php, [cited Aug 20, 2018].

(55) CAMEO Chemicals. https://cameochemicals.noaa.gov/ chemical/3659, [cited Aug 20, 2018].

(56) Wypych, A.; Wypych, G. Databook of Solvents; ChemTec Publishing, 2014.

(57) PubChem. https://pubchem.ncbi.nlm.nih.gov/compound/, [cited May 15, 2018].

(58) Accudynet. https://www.accudynetest.com/visc_table.html, [cited May 15, 2018]. 